I Payload. Apay (lbs) (All variables are normalized by their respective baseline values).

\title{
NEURAL NETWORK AND RESPONSE SURF ACE METHODOLOGY FOR ROCKET ENGINE COMPONENT OPTIMIZATION
}

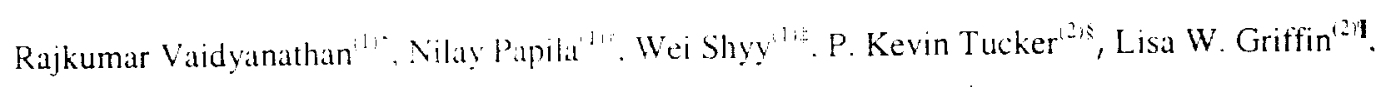 \\ Raphael Hattkat ${ }^{1 / 2}$ and Norman Fitz-Coy ${ }^{1 / \cdots}$ \\ "Department of Acrospace Engineering. Mechanics \& Engineering Science. \\ University of Floridi. Ciainesville. FL 32611-6250 USA \\ 2NASA Mirshall Spatce Flight Center. Huntsville, AL 35812.
}

\section{ABSTRACT}

The goal of this work is to compare the pertormance of response surface methodology (RSM) and two lypes of neural networks (NN) to aid preliminary desien of two rocket engine components. A data set of +.5 traming pornts and 20 rest points. obtained from a semi-empirical model based on

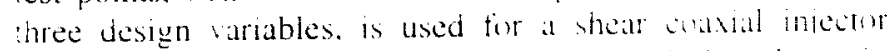
element. Data for supersonic lurbine desien in hased on six design variables. 70 tranning ditat and lis test duta ontamed trom simplified aerodynamic analysis. Several RS and $V . V$ are first constructed using the training data. The test data are then employed to select the best RS or NN. Quadratic and cubic response surfaces. radial basis neural network (RBNN) and back-propagation neural network (BPNN) are compared. Twolivered RBNN are generated using lwo ditferent traming

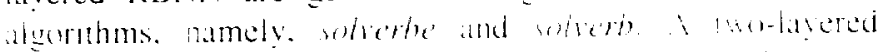
BPNN is generated with Tan-Sigmond transfer functun. Various issues related to the training of the neural networks

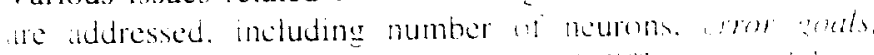
pread constants, and the accuracy 11 driteren modeh 11 representing the desion space. I search thr the optimum design is carried out using a standard. Eradient-based pumizatun alenrithm ower the response surkes represented

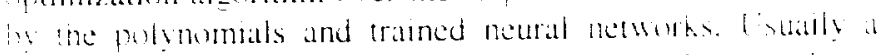
cube polvnomial pertorms heter than the quadratle polynomal but exceptions have been notuced smong the $\mathrm{NN}$ choices. the RBNN designed using solvert vicids more consistent performance for both engine components considered. The training of $\mathrm{RBNN}$ is casier as 11 requites linear regression. This coupled wh the cumsistency in pertormance promise the possibility it it being used as an optimization strategy for engineering design problems.

\footnotetext{
Graduate Student Assistant. Student Member AlAA

Graduate Student Assistant. Student Member AIAA

Protessor and Dept. Charr. Assocrate Fellow M111

S Rerospace Engineer. Member AlAA

Aerospace Enincer. Member AIAA

* Disunguished Professor. Fellow AIAA

** Associate Protessor. Member AlAA

1 INTRODUCTION
}

\subsection{General Background}

Advanced rocket propulsion systems are being proposed to meet goals for increased performance, robustness. and safety while concurrently decreasing weight and cost. These new goals are forcing consideration .1 design valriables over ranges and in combinations not lyprally employed. thereby increasing the design space cumplexity. Objective and efficient evaluation of these new and complex designs can be facilitated by development and implementation if ststematic techniques. Accordingly, Response Surface Methodology (RSM) and Neural Network ${ }^{-}$(NN) techniques have been used to generate surrogate models representing data obtained from complex numerical and experimental simulations. An optimization ilorithm is then used to interrogate these models for intumum design conditions. hased on specified constraints. In this sudy, the preliminary desten assues related to rocket mopuision components. including gas-gas injectors and supersonic turbines have been investigated. The objective this ethert is to ansess retatue pertiomance of RSM and

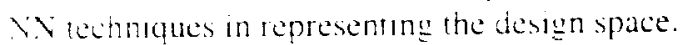

A polynomial-based RSM. in which the design space is represented with quadratic and cubic polynomials in the dependent ariabless is used. The polynomial cretticlents are abtaned by linear regression. The maximum or the minimum of the surface can then be lwaled using a gradient search method. Response Surface methodologies have been used before for rocket engine component design. For example. Tucker et al. ${ }^{3}$ have used RSM for rocket injector design. The approach is not tied to any specific data type or surce. The dimensionality of the data is not a concern. and ciata sbtained through both numerical and experimental methods can be effectively used. RSM enables the designer to combine any number of design variables for different lypes of injectors and propellant combinations. This generality allows the consideration of information at sarying levels of breadth 11.e.. scope of design variables) and depth (i.e. details of the design variabiesi.

The RSM is effective in representing the global characteristics of the design space and it filters noise associated with design data. Depending on the order of polynomial employed and the shape of the actual response surface. the RSM can introduce substantial errors in certain regions of the design space. Shyy et al. ${ }^{4}$ have showed it that 
for a given injector design, a third order response surface performs better than a second order surface. Generation of polynomial based surfaces can be costly for cases involving many of design variables due to the amount of data required to evaluate the coefficients. In tact, the number of coefficients increases rapidly with the order of polynomial. For example, a complete second-order polynomial of $N$ design variables has $(N+I)(N+2) /(2 !)$ coefficients. A complete cubic model has $(N+1)(N+2)(N+3) /(3 !)$ coefficients. The choice of order of the polynomial and the terms to be included depends on the design problem. Many combinations of terms may have to be tried to represent the design space before the best one can be selected.

An optimization scheme requiring large amounts of data and evaluation time to generate meaningtul results is of limited value. While the preliminary designs can be accomplished with empirically based information. detailed designs often require use of data from experiments and/or computational tluid dynamics (CFD) analyses. This data can he time consuming and expensive to generate in large yuantities. Recently. NN have been used to represent the models instead of the more typical polynomal RS.l1. Work in the area of NN by Shyy et al." and Papila el at. have shown that some NN can perform well even when a modest amount of data is available. In particular radial basts neural networks (RBNN) like polynomial based RSM require only linear regression for training and have proven on be particularly accurate. Norgaad et al." and Ross et al. have investgated the feasibility of reducing wind tunnel test tmes by using NN 10 interpolate between meadsurements and demomstrated cost savings. These works have focused on using the $\mathrm{N} V$ to predict data. Attempts to use the nework as a function esaluator and then to link it to the optimizer have been made hy lrotzel et al.". Rai and Madavan" and Greenman and Roth"

NN are highly tlexible in tuntional form and hence ran ofter significant potential for representing complex functions. Networks. like RBNN. that are llexible and employ linear regression methods can use both of these properties 10 improve the performance. The number of neurons in the network, size of the region over which the neuron is sensitive. and the training accuracy of the network are some of the parameters that need to be selected in anetwork. These can be determined by comparing the pertormance of $V \mathrm{~V}$ designed with different values of these parameters. Veural nerworks can be effectively used in (wo ways. First. they can be used in conjunction with RSM. In complex regrons of the surface, the NN can be trained using the existing data. The trained NN can then be used to generate additional data to augment existing data, thus possibly enhancing the accuracy of the surface in that particular ared. Such an approach was investigated by Shyyet al th. This work demonstrated that the NN could indeed vield additional information to help generate more accurate polynomial-based response surtaces. Second. NN can generate data to be used directly in conducting gradient-based optimization. In other words. NN can perform the role of cither enhancing the fidelity of a polynomial-based response

- surface. as in the tirst approacb: or generating information as input 10 an optimizer by itself without resorting to a polynomial representation, as in the second approach. Either way, the only function evaluations required are for the points sought by the optimizer. which searches the design space based on the sensitivity of the response to the perturbations in the design variables.

\subsection{Scope}

The present work is aimed at a direct comparison of the RSM and NN techniques in terms of accuracy and efficiency; the hybrid RSM-NN scheme noted above will not be used here. Both techniques are applied to data used in the design of two rocket engine components: a shear coaxial injector and a supersonic turbine. Variations of each technique are evaluated. Both second and third order polynomials will be used for the Response Surface (RS). Two NN schemes, radial basis and the more commonly used back-propagation NNs are used. The same database for each component will be used to train both the RS and the NN. Both will then be linked (1) an optimization procedure. There is little rigorous theory in the literature to establish the desired framework for a clear comparison between the performances of the two techniques. However, this work provides in assessment of the techniques regarding their practical use in the rocket engine component design process.

\section{IPPROACHES}

\subsection{Summary of Inalytical Models and Design variables}

Two components if a rickiel propulsion system have been considered here, the injector and the turbine. First. a shear coaxial injector element that uses gaseous axygen $(G O)$ and gaseous hydrogen $\left(F / H_{2}\right)$ as propellants is used to investigate the relative performance of RSM and $\mathrm{NN}$ in the design of rocket engine injectors. The original data set from Tucker et al ${ }^{3}(45$ design points) is used to generate quadratic and cubic response surfaces for both, energy release afficiency ( $E R E$ ). a measure of injector performance, and chamber wall heat thux (Q). These 45 design points are evenly distributed (wer the design space. $E R E$ was obtained using correlations taking into account combustor length. $L_{\text {irmi }}$ (length from injector to throat), and the propellant velocity ratio. $W N_{1 .}$. The nominal chamber wall heat tlux at a point just downstream of the injector.

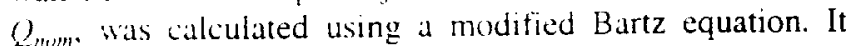
was then correlated with propellant mixture ratio. $O / F$, and propellant velocity ratio, $V N N_{t}$ to yield the actual chamber wall heat tlux, $Q$. The accuracy of each polynomial fit on the original data set is evaluated. Two different types of radial basis NN (RBNN) and a back propagation NN (BPNN) are also trained to represent ERE and $Q$. Each surtace is then used to conduct design optimization over the same range of independent variables. The optimal design points are compared with exact points calculated from the empirical model of Calhoon et al ${ }^{\prime \prime}$. The range of design variables considered in this study is shown in Table 1. Tiventy additional data points that are not used in the generation of response surfaces or the neural networks are 
used to assess the accuracy of different variants of RSM and NN.

The other propulsion system component examined is a supersonic turbine where the preliminary design is conducted by one-dimensional aerodynamic analysis using FpgenML ${ }^{12}$. FpgenML generates a flowpath and runs a preliminary meanline calculation on this flowpath. In this study, a single stage turbine has been considered. There are six design parameters and four output variables involved in this design process. There are 76 design points available for training. These 76 points were selected by using a face centered composite (fcc) design. Instead of 77 design points. as would be provided by a foc design for six vartables, only 76 were available since the meanline code could not converge for one of the designs. The design variables are the mean diameter, $D . R P M$, blade annulus area. $A_{t m n}$. vane axial chord. $C_{r}$, blade axial chord, $C_{b}$, and stage reaction. $k_{r}$. These are parameters influencing the structural properties and pertormance of the turbine. Overall etficiency of the turbine.

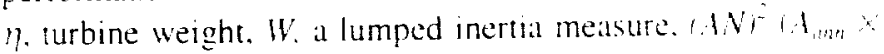
$\left.(R P M)^{\circ}\right)$ and speed at pitchline. $V, D \times R P M$ are chosen as kependent variables. The goal is 10 masmose the meremental payload (Apay) which is derived trom turbine weight (W) and afficiency (1)). Therefore, the objective is a design where $W$ is minimized and $\eta$ is maximized. Due $w$ the structural considerations, constraints have to be imposed un $(A N)^{2}$ and $V_{i n i n}$

Using 18 additional simulations. distmbuted whin the design space, the accuracy of the mudets is lested. The ranges considered for the design varnables and the dependent variables are shown in Egs. $(1)$ and 12 .

For the design variables:

$1 .+96>D>0.0502$

$1.4>R P M>0.0$

$1.3>\Lambda_{i n n}>0.699$

$1.706>C_{1}>0.394$

$1.14 .3>C_{0}>0.264$

1). $0>k_{r}>0.5$

Fir dependent variables:

$1.110>11>0.223$

$1.501>W>0.422$

$-.197>(\mathrm{AN})^{-}>0.343$

$1.849>V_{\text {intit }}>0.0484$

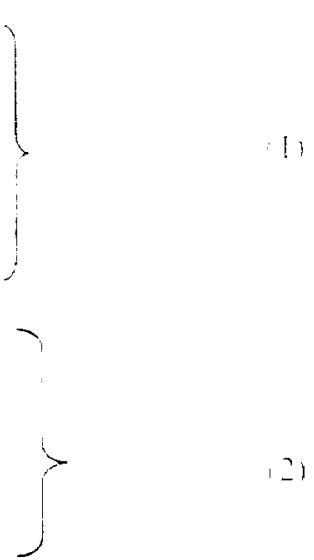

All the variables involved in the design process are normalized by their respective baseline values.

\section{$2.2 \quad$ Objective Functions}

When attempting to optimize two ar more different objective functions, conflicts between them arise because of the different relationships they have with the independent parameters. To solve this problem. a multi-objective ${ }^{12}$ approach is investigated in this study. Here, competing objective functions are combined to a single composite ubjective function. The maximization of the composite function effectively provides a compromise between the individual functions. An average of some form is normally used to represent the composite function. For example, Tucker et $\mathrm{al}^{3}$ used a geometric mean to combine their two objectives, ERE and $Q$. The composite desirability is of the torm

$$
D=\left(\prod_{i=1}^{i} d_{i}\right)^{1 / 1}
$$

where $D$ is the composite objective function, $d_{i}$ 's are normalized values of the objective functions and $l$ is the number of objective functions.

Another way of constructing a composite function is to use a weighted sum of the objective functions. The composite desirability function can then be expressed as

$$
D=\sum_{i}^{\prime} \alpha_{i} f
$$

where $D$ is the composite objective function and $f_{i}$ 's are the non-normalized ubjective functions. The $\alpha_{i}$ 's are dimensional parameters that control the importance of each objective function.

For the injector, the goil is to maximize the energy relealse efficiency, ERE while minimizing the chamber wall heat tlux. $Q$. This is achieved by maximizing a composite objective lunction given by $\mathrm{Eq}(5)$

$D=\left(a_{n,} d,\right)$

There the nomalized tunctums are detined in Eqs. (6) and $\vec{i}$. In the case where a response hould be maximized, such at ERE: the normalized functun takes the form:

$\therefore=\frac{E R E-A}{B-1}$ in $A \leq I R E \leq B$

where $B$ is the target value and $A$ is the lowest acceptable value. We set $d_{F R E}=1$ for any $E R E>B$ and $d_{\text {ERE }}=0$ for $L R E<1$. The choice of $s$ is made based on the subjective importance of this objective in the composite desirability function. In the case where a response is 10 be minimized. such as $Q$, the normalized function takes on the form:

$d_{0}=\left(\frac{E-Q}{E-C}\right)^{\prime}$ for $C \leq E R E \leq E$

where $C$ is the target value and $E$ is the highest acceptable value. We set $d_{Q}=/$ for any $Q<C$ and $d_{Q}=O$ for $Q>E$. $A, B, C$, and $E$ are chosen according to the designer's priorities or. as in the present study. simply as the boundary values of the domain of $E R E$ and $Q$. The value of $t$ is again chosen to reflect the importance of the objectives in the design. In the study $\mathrm{A}$ and $\mathrm{B}$ are equal to 95.0 and 99.9 . respectivelv. Values of $C$ and $E$ are equal to 0.48 and 1.1 , respectively. Both $s$ and $t$ were set to a value of 1 . 
In the case of the turbine, a weighted sum of the two objectives $\eta$ and $W$ has been used. The expression. in the context of the turbine gives the incremental value of the payload with the change in $W$ and $\eta$. The goal is to maximize this incremental value, which in turn results in minimum $W$ and maximum $\eta$.

$D=\Delta p a y=C_{1} \times 100 \times\left(\eta-\eta_{b}\right)-C_{2} \times\left(W-W_{b}\right)$

where $C_{1}=$ the amount of payload increment capacity for any efficiency gain

$C_{2}=$ the amount of payload increment capacity for any weight gain

$\eta=$ the calculated efficiency

$\eta_{b}=$ the baseline efficiency

$W=$ calculated weight

$W_{b}=$ the baseline weight .

The baseline efficiency and weight are obtained using existing design knowledge without henetiting from an uptimization strategy. The weight alssociated with $n$ expressed in percentage, by multiplying it with 100 . in $6^{\circ}$, and the wereht asscriated with $W$ is $C$. This relationship is developed based on detalled turbopump design processes. For ane percent increase in efficiency a payload increase of $C$. Ibs wan be achieved. and as the weight of the turbine increases the rayload has to be correspondingly decreased by a tiator of $C$.

\subsection{Response Surface Methodology ( RSWI)}

Polynomial RSM constructs polynomials of alssumed order and unknown coefficients based on regression analysis. The solutun for the set of costicients that hese his the manne data is a linear least square problem. The number of crefficients to be evaluated depends an the order of potynomial and the number of design parameters inwiled.

kecording to the injector model develuped by (alhown et al". injector pertormance, as measured by $E R E$ depends only on the velocity ratio, $M$, and combustion chamber length. $L_{\text {rumb }}$. Therefore, uniy 15 distinct design points are available for ERE. Since chamber wall heat tlux depends onty on the velocity ratio. $Y A$. and the oxidizer 6 fuel ratio. $O / F$. there are 9 distinct design pounts for $Q$. The design space for this problem is depteted in ligure 1. For ERE. the 5 distinct chamber lengths offer the pulential tor a fourthorder polvnomial fit in $L_{\text {tom }}$. While the thee different velecity ratios limit the fit in $V / V_{1}$, to second order. Quadratic and cubic response surfaces for both ERE and $Q$ have been generated for evaluation. The above-noted limitations on the Jata. limits the cubic surfaces to be third order in $l$....m, only.

is already mentioned. 10 enstruct a complete quadratic polynomial of $\mathrm{N}$ design variables. the number of coefficients required is $(N+1)(N+2) /(2) !)$. In the turbine case with 6 design variables, we would need to estimate 28 coefficients. A complete cubic model would require $(N+1)(N+2)(N+3)(3 !)$ or $8+$ coefficients and four levels.

_. Since the data available is not sutficient to evaluate all the cubic terms, reduced cubic models are eimployed.

The response surfaces were generated by standard kast-squares regression using $\mathrm{JMP}^{14}$. a statistical analysis software package. JMP is an interactive, spreadsheet-based program having a variety of statistical analysis tools. Statistical techniques are also available for identifying polynomial coefficients that are not well characterized by the data. A stepwise regression procedure based on tstatistics is used to discard terms and improve the prediction accuracy. The t-statistic or t-ratio, of a particular coefficient is given by the value of the coefficient divided by the standard error of the coefficient, which is an estimate of its standard deviation. The accuracy of different surfaces at points different from the training data can be estimated by comparing the adjusted root mean square error defined as:

$$
\sigma_{n}=\sqrt{\frac{\sum e_{i}^{2}}{n-n_{n}}}
$$

Here $e_{i}$ is the error at $i^{t h}$ point of the training data, $n$ is the number of training data points and $n_{p}$, is the number of coefficients. When the data contains uncorrelated Gaussian moise. $\sigma_{t}$ provides an unbiased estimate of that noise. Even when the error is not solely due to noise $\sigma_{i t}$ provides a good overall comparison among the different surface fits.

The accuracy of the models in representing the objective functions is also gauged by comparing the values if the whective function at test design points, different from those used to generate the tit. The root mean square arror. $\sigma$. for the test set is given by:

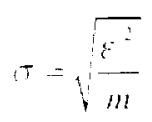

In this equation $\varepsilon$, is the error at the $i^{\text {it }}$ lest point and $m$ is the number of test points.

\subsection{Veural Networks}

Two different types of $\backslash \mathrm{N}$ have been used, namely radial basis ${ }^{15}$ and back-propagation ${ }^{15}$. The training process of the network is a cyclic process and the weights and biases of the nodes of the network are adjusted until an wcurate mapping is abtained. This trained network can then predict the values of the objective for any new set of design variables in the design space. The neural network toolbox ${ }^{15}$ available in Matab is used for the current unalysis.

\subsubsection{Radial Basis Neural Networks (RBNN)}

Radial-basis neural networks are two-layer networks with a hidden layer of raldial-basis transfer function and a linear output layer (Figure 2). RBNN requires large number of neurons, depending on the size of the data set. but they can be designed in a small amount of rime. This is due to the fact that the process of determining the-weights associated with the large number of neurons uses linear regression. Thus, they may be efficient to train when there are large amounts of datid available for training. 
The transter function for radial basis neuron is radbas, which is shown in Figure 2b. Radbas has maximum and minimum outputs of 1 and 0 . respectively. The output of the function is given by

$$
u=\operatorname{radbas}(\operatorname{dist}(w, p) \times b)
$$

where radbas is the transfer function. dist is the vector distance between the network weight vector. $w$ and the input vector, $\boldsymbol{p}$, and $b$ is the bias. In a radial basis network (Figure 2a) each neuron in the radbas hidden layer is assigned weights, $w_{l}$ which are equal to the values of one of the training input design points. Therefore, each neuron acts as a detector for a different input. The bias for each neuron in that layer, $b_{1}$ is set to $0.8326 / s c$, where $s c$ is the spread constant. a value defined by the user. This defines the region of intluence by each neuron. The whole process is then reduced to the evaluation of the weights, $w_{2}$, and biases, $b_{2}$. in the output linear layer, which is a linear regression problem. If the input 10) a neuron is identical to the weight vecter, the outpul of that neuron is 1, since the effective input (1) the transter function is zero. When a value of 0.8326 is passed through the transtier function the output is 0.5 . For a vector distance equal to or less than $0.8320 / 6$. the output is 0.5 or more. The pread constamt defines the radius of the design space over which a neuron has a response of 0.5 or more. Small values if si can result in poor response in a domain not closely lowated an heuron positions. that is. for inputs that are fiar from the ranning datal as compared to the detined radius. the responte trom the rearon will be negligible. Large values will result in has sensitivity of neurons. Since the radius of sensitivity is larese neurons whose weights are ditferent from the input wites by a large amount wall still hate high output thereby resulung in .l liat nemork. The best value of the spread consiant for some cest data can be found by comparing $\sigma$ for networks wh ditferent spread instants

In Matab, radial-basis nemwhis can he destgned using two different design procedures. wholpe and solverh. Solverbe designs a network with zero error on the training vectors by creating as many radial basis neurons as there are input sets. Theretore solverbe may result in a larger nework than required and map the newwork exalcty. thereby titting numerical noise. A more compact desien in lerms of nework ize ts obtained from solverb. which ereates me neuron at at lime to minimize the number ut neurons required. At each epoch or cycle. neurons are added to the network till a user specified RMS error is reached or until the network has the maximum number of neurons possible. The design parameters for solverb are the spread constant, a user defined RMS uror aral, and the maximum number ot epochs whereas it is only the spread constant tor solverbe.

In case of the injector design there are two objectives, namely $E R E$ and $Q$ and for turbine the objectives are $\eta$ and $W$. Figures 3 and 4 give the variation of $\sigma$ for the network design with solverbe for the objective functions of the two engine - components. In case of solierb' the error goal during training Aso detines the accuracy of the network. In objective of litting a numerical model is a remove the noise associated with the data. A model, which maps exactly as solverbe does, will not eliminate the noise, whereas solverb will. Figures 5 and 6 give the variation of $\sigma$ for the network design with solverb for the objective functions of the two engine components.

By comparing Figures 3-6 it can be seen that for low values of spread constant the NN network has a poor performance. As the spread constant increases $\sigma$ asymptotically decreases. However, as demonstrated by Figure $5 \mathrm{a}$ the performance of the network can deteriorate for higher values of the spread constant. The region with a large variation in $\sigma$ is highly unreliable because this indicates a high sensitivity of the model to a small variation of spread constant and possibly the test data, in this region. Hence the desirable spread constant is selected from the region where the performance of the network is relatively consistent.

Figures 5 and 6 also show the influence of error yoal on the network. Generally if a network maps the traning data accurately it cin he expected to perform efficiently with the test data. However, accurately mapping nossy data may result in poor prediction capabilities for the network. The variation in the pertormance is not significant except for the ERE and $Q$ network (Figure 5), where the poor pertormance of the network at high values of spread constant improves for a latger error goal. This may indicate the presence of noise in the data for $E R E$, which solerb is able to eliminate with an appropriate e'ror goal. Figure $\rightarrow$ hows variations in number of epochs and $\sigma$ with the variation of error eod for a given spread constant when RBNN is designed with solverb. The number of neuroms in the network is anc more than the number of epochs. (one expects that as the cror goal increases the number at epochs becomes smaller and the network pertorms less accurately als in Figures $7 \mathrm{a}$ and $7 \mathrm{~b}$. However as demonstrated by Figures $7 \mathrm{c}$ and $7 \mathrm{~d}$. a more stringent iror eoal for the traning data does not necessarily result in better predictive capability aganst the test data. Less accurate nework can be designed for these objectives. which have smaller prediction error.

When choosing an appropriate network the abovementioned faatures have to be considered. The pertormance if the constructed NN is best judged by comparing the prediction error as given in Eq. 10 \%, for different networks Using solverbe. networks are designed with varying spread constants and the one that yields the smallest error is selected. When solverb is used, networks are designed for different spread constants and error goals. The network that gives the smallest error for the test data is used. The details ot the networks selected are discussed in later sections.

\subsubsection{Back-propagation Neural Networks (BPNN) \\ Back-propagation networks are multi-layer} networks with hidden layers of sigmoid transfer function and a linear output layer (Figure 8). The transfer function in the hidden layers should be differentiable and thus, either log-sigmoid or tan-sigmoid functions are typically used. In this study. a single hidden laver with a tan-sigmoid transfer 
function. tansig, (Figure 8 b) is considered. The output of the function is given by

$a=\operatorname{tansig}(u+p+b)$

where tansig is the transfer function. $w$ is the weight vector, $p$ is the input vector and $b$ is the bias vector. The maximum and minimum outputs of the function are 1 and -1 . respectively.

The number of neurons in the hidden layer of a backpropagation network is a design parameter. It should be large enough to allow the network to map the functional relationship. but not too large to cause overfitting. Once it has been chosen, the network design is reduced to adjusting the weight matrices and the bias vectors. Since for BPNN the unknown weights are in the nonlinear function. the training process requires nonlinear regression. Which is an optimization process. This optimization is usually performed using grad

ient methods. In Matlab, back-propagation networks can be trained by using three different training tunctions. tranbp. rambpr and trainlm. The first two are hased on the steepest descent method. Simple back-propagatum wh thambp is usually slow since it requires small learning rates for stable learning. Traimbpx, applying momentum or adaptive learning rate, can be considerably faster than trambp, but trainlm. applying Levenberg-Marquard optimization, is the most efficient since it is hased on a more efticient uprimization algorithm.

The design parameters fir thathim are the number of neurons in the hidden layer. al user detined error worl. and the maximum number of epochs. The traning contmues until

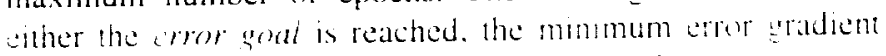
iccurs or the maximum number of epochs has been met.

For BPNN, the initial weights and biases are randomly generated and then the optimum weights and biases are evaluated through an iterative process. The weights and hialses are updated by changing them in the directorn of down lope with respect to the sum-squared error of the network. which is to be minimized. The sum-squared error is the sum of the squared error between the network prediction and the ktual values of the output. In BPNN lligure sal the weights. w. and biases. $b_{l}$, in the hidden fansig laser are not tixed as in the case of RBNN. Hence. the welghts have at nonlinear relationship in the expression between the inputs and the rutputs. This results in a nonlinear regression problem. which lakes a longer time to solve than RBNN. Depending upon the initial weights and biases. the convergence to an optimal network design may or may not be achieved. Due to the randomness of the initial guesses. if one desires to mimic the process exactly for some purpose, it is impossible to re-train the network with the same accuracy or convergence unless the process is reinitiated exactly as before. The initial guess of the weights is a random process in Matlab. Hence to re-train the network the initial guess has to be recorded.

The architecture is decided based on past experience - with similar kind of dataset. For a given objective the error ural is tixed and the number of hidden layer neurons are aried between 2 and the total number of inputs. Each network setrained few times so als to start the search from random initial weights and biases. The networks that do not achieve the error goal are discarded. Among the converged networks the selection of the best network is made based on the value of $\sigma$. The goal is to attain as low a value for $\sigma$ as possible. The number of neurons in the hidden layer is increased one at a time till the error goal is achieved and a small value of $\sigma$ is obtained. Although this method may not be the best way to obtain the best BPNN. it is considered adequate for the current study. At times larger network has a high value of $\sigma$. which maybe due to overfitting of the design space. To prevent the model from converging to a local minimum, an iterative method is used as suggested by Stepniewski et al ${ }^{16}$. The obtained network is retrained with initial weights obtained by perturbing the weights of the obtained network.

$w^{\prime}=w_{1,}+\lambda w$

where $w$ is the initial weight vector for the network to be trained. $w_{n}$ is the weight vector of the obtained network. $\lambda$ is the level of perturbation $(0.1)$ and $r$ is a matrix of random numbers between -1101 .

\subsection{Design Optimization Process}

The entire optimization process can be divided into two parts:

1) RS/NN training phase for establishing an approximation.

-) Optimizer phase

In the first phase. RS or NN are generated with the avilable training data set. In the second phase the uprimizer uses the RS/NN during the search for the optimum until the timal converged solution is obtained. The imitial set of design variables is randomly selected from within the design space. The tlowchart of the process is hown in Figure 9.

The iptimization problem at hand can be firmulated as min $\{f(x)\}$ subject to $b \leq x \leq u b$. where $b$ is the lower boundary vector and $a b$ is the upper boundary vector of the design variables vector $x$. If the goal is to maximize the objective function then $f(x)$ can be written as - a $(x)$. where $g(x)$ is the objective function. Additional linear ir monlinear constraints can be incorporated if required. The present design process does not have any such additional constraints. The optimization toolbox ${ }^{17}$ in Watlab used here employs a sequential quadraticprogramming algorithm.

\section{RESULTS AND DISCUSSION}

The RS and NN are constructed using the training data. The test data is then employed to select the best RS or NN. Specitically in RSM. the difference between the RS and the training data, as given by Eq. (9), is normally used to judge the performance of the fit. The additional use of the 7est data helps to evaluate the performance of different polynomials over design points not used during the training phase. This gives a complementary insight into the quality 
of the RS over the design space. For both the rocket engine components, different polynomials were tried. Table 2 compares the performance of different polynomials used to represent the two objective functions of the injector case. $E R E$ and $Q$. Starting with the all the possible cubic terms in the model. revised models are generated by removing and adding terms. Similar kind of analysis is also done for the turbine case. The best polynomial is selected based on a combined evaluation between $\sigma_{a}$ and $\sigma$.

For the NN, the test data helps evaluate the accuracy of networks with varying neurons in BPNN and varying spread constant in RBNN. Thus the test data are part of the evaluation process to help select the final NN. Based on the RSM or NN model, a search for optimum design is carried out using a standard, gradient-based optimization algorithm over the response surfaces represented by the polynomials and trained neural networks.

\subsection{Shear-Coaxial Injector}

According to the available datia the infectur pertormance. ERE. depends oniy on the velocity ratu. IA.. and combustion chamber length. L, wan. which indicates 15 distinct design points for ERE. The chamber wall heat nlux. (2) depends on velocity ratio. $V V_{0}$, and oxidizer to fuel ratio. $O / F$, and has nine distinct points. For ERE. as seen from Figure 1, five distinct levels for $L_{c o m}$, offers the potential for at fourth-order polynomial fit in the same, while three different velocity ratios and oxidizer to fuel ratur limit the tit in these wiriables to second order.

A reduced quadratic and an incomplele cubsc response surfaces are used for the two objectwe functions. The lirst model in Table $2 a$ and the sixth model in Table 2 th are the welected cubic models for $L R E$ and (1) respectively. There in no noticeable improvement among the remaining cubic model fir ERE. For $Q$, the selected model is the best in terms of $\sigma_{*}$. although there are other models with identical value of $\sigma$.

$$
\begin{aligned}
& \angle R E=70.43+1.580 \mathrm{~V} / \mathrm{I}+0.208 \mathrm{~L} \ldots-1) .1901 \mathrm{~L}: 1 \% \\
& -0.331\left(L_{\text {man }}\right)^{2} \quad 11+ \\
& \underline{1}=0 .+79-0.0400 / F+0.191 \mathrm{H} / \mathrm{H}-0.00096 / \% \\
& -0.02810 / \mathrm{FH} / \mathrm{H}
\end{aligned}
$$

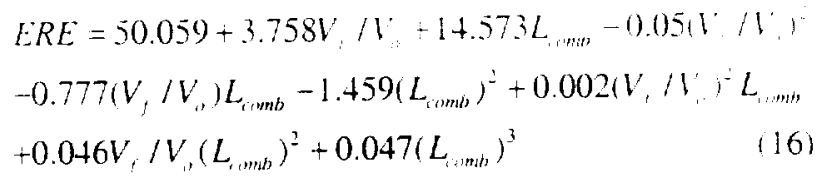$$
2=-10.560-0.3580 / F+0.383 \mathrm{~V} / \mathrm{V}-0.019110 / \mathrm{F}
$$$$
-0.107(O / F) V_{i} / V_{n}-0.003\left(V_{t} / V_{0}\right)^{2}+0.005(O / F)^{-} V_{t} / V_{.}
$$$$
+0.002(O / F)\left(V_{1} / V_{1}\right)^{2}
$$

-- Equations $(14)$ and $(15)$ are the reduced quadratic responses and Eqs. (16) and $(17)$ represent the reduced cubic polynomials used for the two robective tunctions. The t- statistics for the coefficients in Eq. (14) vary between 49.30 and 8.06. For the coefficients in Eq. (15), they vary between 6.28 and 0.52 . In Eqs. (16) and (17), the t-statistics of the coefficents vary between 14.69 and 0.31 and 3.36 and 0.74 , respectively.

The radial basis networks designed with solverbe are the largest with 15 neurons in the hidden layer for $E R E$ network and nine neurons for the $Q$ network. Solverb designs a network for $E R E$ with 14 neurons in the hidden layer and a network for $Q$ with eight neurons. Compared to RBNN. BPNN has fewer neurons, the number of neurons in the hidden layer are eight and four for the ERE and $Q$ networks, respectively. Details of the networks used are listed in Table 3. The spread constant used for RBNNs and the error goal of the training data is also given in Table 3 . The spread constant values are selected from the region where the performance of the network is consistent with the variation of spread constant (Figures 3-6). The error goal, in the case of solverb, is selected based on the network with the hest performance for the ideal spread constent (Figure 71 .

The error in predicting the values of the objective lunction by different schemes is given in Table 4 . Several observations can be readily made.

1. Both NNs perform better than the RSM for this data set.

2. Both solverbe and solverh are of comparable performance.

$\therefore$ The BPNN helps generate smaller networks and pertiorms at par in comparison to RBNN.

4. The cubic polynomial is more accurate than the quadratic one.

The various modeis generated are compared with test dala in Figures 10 and 11 . The curves representing the VN predictions are closer to the data obtained from the injector model than the RSs thereby demonstrating that NN models are able 10 predict better than the RSs. BPNN pertorms as well as RBNN hut tends to be that. Due to its lower order. the quadratic polynomial is flat. The cubic polynomial is able to perform better than quadratic.

The optimum solution obtained from various shemes is shown in Table 5 and Figures 12 and 13. The aim is (1) maximize ERE and minimize $Q$. The trend of the bbjective tunctions in the design space is monotonic and hence every modet is able to select identical optimum design fir the given constraints. The thatness of the polynomials results in bad predictive values of the objective function for the optimum design. The cubic polynomial is more flexible than quadratic but is not consistent. For a $l / N$, constraint of 4 the quadratic polynomial is more accurate but for higher values of $V N_{0}$, the cubic polynomial is more accurate. In contrast. the NN models are able to perform well. Since the optimum design happens to be the same als one of the training points, solverbe is able to predict the values of the objective function accurately. Solverb performs equally well, thereby showing the capability of performance with fewer neurons. Pertormance of BPNN is not als satisfactory as suggested in Table. 4. For lower constraints of $V \mathcal{N}_{n}$, it performs poorly 
but for higher values of $V / N_{0}$ it is good. This maly be due to the selection of fewer neurons in the hidden layers of the networks. Overall, it is still better than to the RSM and demonstrates the flexibility of NN over RS.

As stated by Papila et al ${ }^{5}$, when it comes to choosing between NN and polynomials, polynomials are easy to compute. The number of coefficients might be numerous but the linearity of the system expedites the process of coefficient evaluations. This is also the reason RBNN train fast. On the other hand, the weights of BPNN are evaluated through a nonlinear optimization, which slows the training process. Of all the NN presented here, the one designed with the help of solverbe is the fastest to train since the values of the weights are set to values of the input dependent variables. Solverb trains with the addition of one neuron at a time with weights similar to the input and hence is slower.

\subsection{Supersonic Turbine}

The generation of RS and the training of the NNs are done with the 76 design points in Table $5 \AA$. The analysis was initially done without the constraints and then wh the constraints on $(A N)^{-}$and $V$.

A quadratic RS was initially generated. Then. cubic terms were included. Cubic terms that are products of three different variables were included becaluse il the number of data available and the number of levels being three. The trend of the design data also suggests the presence of some of these kerms. Therefore, the initial cubic equation has ti kerms. A reduced third order $R S$ s for $\eta$ and $W$ wals selected hatsed on the relative performances of different pulynomals obtatined by removing terms from the initial cubic equation hased on 1itatistics. The cubic cquation was selected bitsed on the coaluated value of $\sigma_{i:}$ and $\sigma$. lable 6 suggests that the reduced cubic polynomial is better than the quadratic polymomial since $\sigma_{1,}$ is better for the former. The values ol $\sigma$ are comparable

The t-statistics for the coeftictents in the response urface of 17 varies between 179.72 and 1.2 . The sodtielents in the response surface of $W$ have t-statistles faryng between $\$ 22.60$ and 0.68 . The response surtaces for $\|$ and 11 are as follows:

$$
\begin{aligned}
& \eta=0.65+2.9170+5608.217 R P M+1.1287 .1 \\
& -0.00729 C+0.005+4 C,-0.0399 k,-282 D \\
& -10283.057 \mathrm{D} \cdot \mathrm{RPM}-1.572 \times 10 \mathrm{RPM}+5.228 \mathrm{DI} \\
& -13461.823 A_{m} R P M+0.0247 C D-114.467 C R P H \\
& -0.00647 C_{r}^{2}-0.0124 C_{b}^{2}-0.163 k_{r} D-300.440 k_{r} R P M \\
& -0.429 k A_{1 \ldots}-0.00608 k C_{i}-0.00362 k C_{i}-0.0128 k_{1}=
\end{aligned}
$$

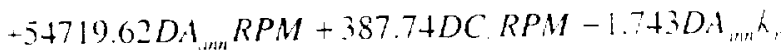

$$
\begin{aligned}
& -0.037 D C_{k} k_{r}-5384.729 A_{u n n} R P M k \\
& -113.868 C_{i_{1}} R P M k
\end{aligned}
$$

$$
\begin{aligned}
& -13.012 A_{\text {ann }}^{2}+0.00856 C_{v} D+10.744 C_{v} R P M \\
& -0.00342 C_{1}^{2}-0.0104 C_{,} D-23.359 C_{b} R P M \\
& +0.0127 C_{k} A_{a, n}-0.00609 C_{n}^{2}-0.0686 k, D \\
& +93.527 k R P M-0.227 k_{r} A_{i m n}-0.00324 k_{r} C_{v} \\
& -0.00183 k, C_{i,}-0.00673 k_{r}^{2}+93.193 D C_{v} R P M \\
& -162.604 D C_{1} R P M+921.053 D k, R P M \\
& +0.342 D A_{a n n} C_{b}-0.692 D A_{i m n} k_{r}-0.0162 D C_{i} k_{r} \\
& -11.311 C R P M k \text {, }
\end{aligned}
$$

The networks designed with solverb have 37 and 75 neurons for $\eta$ and $W$. respectively in the hidden layer, while those designed with solverbe has 76 neurons each. The BPNN uses significantly less number of neurons by generating networks with five and 60 neurons for $\eta$ and $W$, respectively, in a single hidden layer. The $\mathrm{NN}$ architectures chosen are listed in Table 7.

The accuracy of the various models is tested with the data avalable in Table $6 \mathrm{~A}$ and the error is shown in Tables. Solverbe has a poor prediction for $n$. which might be due to overtitting, but pertorms well for $W$. The outcome if Table $\&$ for the supersonic turbine is similar to that of Table 4 for the injector. except that BPNN is clearly interior to RBNN. Overall. based on the (wo cases, it seems that solvel is most consistent among all methods evaluated.

The intimum wlutions subiected to the constraints. if A.V limited to less than 1.132 (normalized with baseline value and $V_{i t r}$ is limited to less than 1.148 normalized with haseline value), are prexented in Table 9. since $A$ A is proportonal on the product of square of $R P M$ and $A_{\text {min }}$ and $V_{\text {rim }}$ is proportional a $D$ times RPM. no NN/RS is generated for them. By comparing the predicted ontimal design hy the various methods, one observes that wherbe and BPNN vield noticeably larger errors in $\eta$ and II. respectively. Solverb and the response surface are more consistent with both $\eta$ and $W$. Judged by the error in predicting Jpay, it seems that the RSM is most accurate. lowever. snce the real goal is to maximize $\Delta p a y$. it is important w note that the actual value of Spay for the uptimal desien chosen by the RSM is the worst. Clearly, the lares multiplier in $\mathrm{Eq}$. (8) causes bias in relative welghting between $\eta$ and $W$, which in turn causes different "apparent" accuracy levels by various methods.

From a design perspective, it is interesting to understand the impact of the constraints from $A_{\text {ann }}$ and $V_{\text {puch }}$ in the optimal turbine parameters. Such an assessment is ortered in Figures $1+$ and 15. As D. RPM and $A_{i n n}$ decrease. 7. $W . V_{\text {pirth }}, A N^{-}$and $\Delta p a y$ decrease. $C_{b}$ and $C_{v}$ are almost constant over the design space and they do not have any noticeable effect on the objective functions and constraints. In the case of $C l$, the BPNN shows a small perturbation for the analysis with the constraint. This might be due to the mapping of some noise by BPNN. Otherwise it is unaffected by the inclusion of the constraints. The stage reaction. $K$, is unatiected as expected, since we are dealing 
AIAA-2000-4880

only with the single stage of the turbine. Hence there is no split on the stage reaction.

\section{SUMMARY AND CONCLUSIONS}

In the present study, the RS and $\mathrm{NN}$ are first constructed using the training dati. The test data are then employed to assess the pertormance af various polynomials and to offer insight into model improvement by removing and adding terms. The best polynomial is selected based on a combined evaluation between $\sigma_{t}$ and $\sigma$. For the NN, the test data helps evaluate the accuracy of networks with varying neurons in BPNN and varying spread constants in RBNN. Thus the test data are adopted to help select appropriate RSM and NN models. Once an RSM or NN model is constructed. at search for optimum design is carried out using a standard. gradient-based optimization algorithm over the response surfaces represented by the polynomials and traned neural networks.

Based on the results ohtaned. we have reached the following conclusions

1. Higher order polynomials pertorm beter than lower arder polynomials as they have more llexibility. However. appropriate statistical measure needs of he laken wo determine the best terms to include.

2. In the present study, both NN and RSM can perfiorm comparably for modest data sizes.

$\therefore$ Among all the NN configurations. RBNN designed with werb scems to be more consistent in pertormance tion both injector and turbine cases.

4. Radial basis networks, even when designed etticiently with solvert. tend to have many more neuroms than a comparable back-propagation win lan-sigmold wo logsigmoid neurons in the hidden laver. The hase reason fin this is the fact that the sigmoid neurons can have utputs were a large region of the inpue pace. while radial hasis neurons anly respond for relateds smath regens of the input spake. Thus, larger input spaces regure more malal basis meurons for training

$\therefore$ Contiguring a radial basis network often lakes less tume than that for a back-propalgation network because the traniner process for the former is a lincar in nature.

0. RBNN with the combined fatture if thexibility and tineat regression is more accurate than BPNN. which is nonlinear.

Based on the results shown in liables $t$ and $s$. it is seen that the RBNN technique performs consistentiy, and holds promise for the design/optimization of advanced rocket propulsion components. The method adopted here to generate BPNN is not necessarily the most etticient. Given at better method of making the selection of the number uf neurons in the hidden layer. BPNN, might be able 10 pertorm better. Future work would be aimed at implementing a better designing procedure for back-propagation networks. The work has been carried out with modest data sizes and the training is last for such cases. Issues, related wh the number of design - variables and training data size are criticat for practical design applications. and should be addressed in the future.

\section{ACKNOWLEDGMENT}

The present study has been supported by NASA Marshall Space Flight Center.

\section{REFERENCE:}

1. Myers, R. H. and Montgomery, D. C., Response Surface Methodolog: - Process and Product Optimization Using Designed Experiment, John Wiley \& Sons, 1995.

2. Hertz. J., Krogh, A. and Palmer, R. G., Introduction to the Theory of Neural Computation. Lecture Notes Volume I, Addison-Wesley Publishing Company, 1992.

3. Tucker, P. K.. Shyy. W. and Sloan, J. G., "An Integrated Design/Optimization Methodology For Rocket Engine Injectors." $34^{\text {th }}$ AIAA / ASME / SAE / ASEE Joint Propulsion conterence and Exhibit. July 13-15. 1998 AIAA-98-3513. Cleveland. OH.

4. Shyy, W.. Tucker, P. K. and Vaidyanathan, R., "Response Surface and Veural Nerwork techniques for Rocket Engine hijector Optimization." $35^{\text {th }}$ AIAA / ASME / SAE / ASEE Joint Propulsion Conference and Exhibit. June 20-24. 1999. AIAA-99-2455, Los Angeles. CA.

5. Papila. N., Shyy, W.. Fitz-Coy. N. and Haftka, R. T., "Assessment of Vearal Vet and Polynomial-Based Firhmiques for Aerecinamic ipplicarions." $17^{\text {th }}$ spplied Aerodynamics Conterence. June 28 -July 1. 1999. ALA-99-3167. Nirfolk. VA.

6. Vorgatard. M. Jorgenson. C. C. and Ross. J. C.. "Venal Setwork Predichon of Ven Aercratt Design Ciefticients,"NASA TM1-112197.1997

7. Russ. J. C.. Jorgenson. ('. C. and Norgaard, M., "Reducing Wind Tamel Data Requirements Using vetural Venorks. VAS1 TM-112193. 1997.

Protzel. P. W. Palumbo, D. L. and Arras, M. K.

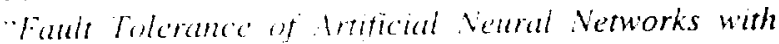
spplications in Critical Sistems." NASA Technical Paper 3187.

1). Rai. ... M and Madavan. X. K.. "Terodrnamic Design l'sing Neural Nerworks." VAA Paper No. 98-4928.

10. Greenman. R. M. and Roth. K. R., "High-Lift Optimiation Désign l'sing Veural Vetworks on a Multi-Element dirfoil." Proceedings of DETC 98 , ASME 1998 Computers in Engineering Conference.

11. Calhoon. D.. Ito, J. and Kors, D.. "Investigation of Gaseous propellant Combustion and Associated Injector-Chamber Desten Gindelines." Aerojet liquid rocket company. NASA Cr-121234. Contract NAS313379. July 1973.

12. Papila. N.. Shyy, W., Griffin. L. W.. Huber, F. and Tran, K.. "Preliminary Design Optimization For A Supersonic Turbine For Rocket Propulsion," $36^{\text {th }}$ AIAAVASME/SAE/ASEE Joint Propulsion Conference and Exhibit, Paper No. 2000-3242 (2000). Huntsville. IL. 
13. Haftka, R. T., Gurdal, Z. and Kamat, M. P.. Elements of Structural Optimization, $3^{\text {rd }}$ edition, Kluwer Academic Publishers, 1990.

14. SAS Institute Inc. (1995). JMP version 3. Cary, NC.

15. Dernuth, H. and Beale M., Matlab Vearal Norwork Toolbox, The Math Works Inc, 1992

16. Stepniewski, S. W., Greenman. R. M.. Jorgensen. C. C. and Roth, K. R., "Designing Compact Feedfoniard
Neural Models with Small Training Data Sets," $38^{\text {th }}$ AIAA Aerospace Sciences Meeting and Exhibit, January 10-13, 2000.

17. Coleman, T., Branch, M. A. and Grace, A., Optimization Toolbox for Use with Matlab, Version 2. The Math Works Inc. 1999

\begin{tabular}{|c|c|c|}
\hline$O / F$ & $V N_{b}$ & $L_{c o m b}$, in. \\
\hline 4.6 .8 & 4 & $4.5,6,7,8$ \\
\hline 4.6 .8 & 6 & $4,5.6 .7,8$ \\
\hline $4.6,8$ & 8 & $4.5,6.7 .8$ \\
\hline
\end{tabular}

Table 1: Range of design variables considered for the shear coaxial injector element

\begin{tabular}{|c|c|c|c|c|c|}
\hline $\begin{array}{c}\text { Model } \\
\#\end{array}$ & Coefficient $=0$ & $\begin{array}{c}\text { Terms } \\
\text { Removed }\end{array}$ & Terms Included & $\sigma_{a}(\%)$ & $\sigma(\%)$ \\
\hline l & & VMO & Quadratic and less & 0.218 & 0.280 \\
\hline 2 & $V / N o$ & & & 0.0857 & 0.212 \\
\hline 3 & $V N o$ & 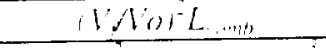 & & 0.0799 & 0.214 \\
\hline 4 & & 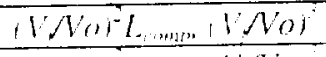 & & 0.0799 & 0.214 \\
\hline 5 & & 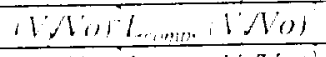 & $\left(L_{\text {mamb }}\right)^{\circ}$ & 0.0859 & 0.213 \\
\hline 0 & & 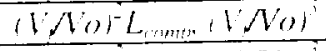 & 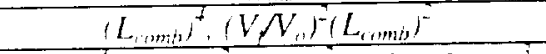 & 0.0936 & 0.212 \\
\hline 7 & & 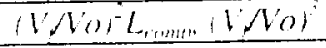 & 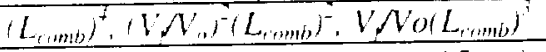 & 0.0988 & 0.212 \\
\hline
\end{tabular}

Table 2(a): Different cubic polynomials tor $E R E$. (Dependent variables: $V, N_{,}$and $L_{\text {romb }}, 15$ training points,

10 test points) (Errors are given in percentages of the mean value of the responses).

\begin{tabular}{|c|c|c|c|c|c|}
\hline $\begin{array}{c}\text { Model } \\
\$\end{array}$ & Cuetticient $=0$ & $\begin{array}{c}\text { Terms } \\
\text { Remused }\end{array}$ & Terms Included & $\sigma_{1,1}\left(\sigma_{1}\right)$ & $\sigma(\%)$ \\
\hline 1 & & $(O / F)^{-}$ & ()uadratic and less & 5.445 & 3.490 \\
\hline 2 & $(V A O)^{\prime} .\left(O / E^{\prime}\right.$ & & & 5.584 & 2.234 \\
\hline$\therefore$ & $(0 / F)^{i}$ & $110)^{-}$ & & 5.584 & 2.094 \\
\hline+ & & $(1 / 10)^{\circ} \cdot(0 / F)^{i}$ & & 5.584 & 2.094 \\
\hline 5 & & blol $(\mathrm{O} / \mathrm{F})^{\mathrm{i}}$ & & 5.584 & 2.234 \\
\hline 6 & & $(\mathrm{NAO}) \mathrm{OOF})^{2},(\mathrm{WNO})^{2}$ & & 3.909 & 2.094 \\
\hline 7 & & 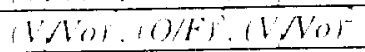 & $(\mathrm{NOO} / \mathrm{O} / \mathrm{F})^{-}$ & 5.584 & 2.094 \\
\hline
\end{tabular}

Table 2(b): Ditferent cubic polynomials to $Q$. (Dependent variables: $O / F$ and $V / V$. 9 trainung points. + test points) (Errors are given in percentages of the mean value of the responses).

\begin{tabular}{|c|c|c|c|c|c|c|c|}
\hline \multirow[t]{2}{*}{ Scheme } & \multirow[t]{2}{*}{$\begin{array}{l}\text { \#of } \\
\text { Lavers }\end{array}$} & \multicolumn{2}{|c|}{$\begin{array}{l}\text { \# ot neurons in } \\
\text { the hidden layer }\end{array}$} & \multicolumn{2}{|c|}{$\begin{array}{l}\text { \# of neurons in } \\
\text { the sutput laver }\end{array}$} & \multicolumn{2}{|c|}{ Error goal aimed for during training } \\
\hline & & $E R E$ & 2 & $E R E$ & 2 & $E R E$ & $Q$ \\
\hline RBNN (Solverbe) & 2 & 15 & 9 & 1 & 1 & $0.0(x c=3.25)$ & $0.0\{s c=1.20\}$ \\
\hline RBNN (Solverb) & 2 & 14 & $\therefore$ & 1 & 1 & $0.001\{s c=1.05\}$ & $0.001\{s c=1.05\}$ \\
\hline BPNN & 2 & 8 & + & $!$ & 1 & 0.01 & 0.01 \\
\hline
\end{tabular}

Table 3: Neural Network architectures used to design the model for shear coaxial injector element. [ $s c=$ spread constant\}

\begin{tabular}{|c|c|c|}
\hline Scheme & $\sigma$ for ERE $(\%)$ & $\sigma$ for $Q(c)$ \\
\hline RBNN (Solverbo) & 0.207 & 1.396 \\
\hline RBNN (Solverb) & 0.133 & 1.536 \\
\hline BPNN & 0.180 & 0.832 \\
\hline Partial Cubic RS & 0.213 & 2.234 \\
\hline Quadratic RS & 0.280 & 3.490 \\
\hline
\end{tabular}

Table 4: RMS error in predicting the values of the objective function by various schemes for the shear coaxial injector element (Errors are given in percentages of the mean value of the responses). 
AIAA-2000-4880

\begin{tabular}{|c|c|c|c|c|c|}
\hline$V / N_{0}$ & Scheme & $O / F$ & $L_{c o m b}$, in. & $E R E, \%$ & $Q, \mathrm{Btu} / \mathrm{in}^{2}-\mathrm{sec}$ \\
\hline \multirow[t]{7}{*}{4} & RBNN (Solverbe) & 8.0 & 7.0 & $98.60(0.00)$ & $0.588(0.00)$ \\
\hline & RBNN (Solverb) & 8.0 & 7.0 & $98.60(0.00)$ & $0.588(0.00)$ \\
\hline & BPNN & 8.0 & 6.9 & $98.64(0.14)$ & $0.578(1.70)$ \\
\hline & Partial Cubic RS & 8.0 & 7.0 & $98.61(0.01)$ & $0.594(1.02)$ \\
\hline & Quadratic RS & 8.0 & 7.0 & $98.67(0.07)$ & $0.591(0.51)$ \\
\hline & Model & 8.0 & 7.0 & 98.60 & 0.588 \\
\hline & Model & 8.0 & 6.9 & 98.50 & 0.588 \\
\hline \multirow[t]{6}{*}{6} & RBNN (Solverbe) & 8.0 & 7.0 & $99.20(0.00)$ & $0.512(0.00)$ \\
\hline & RBNN (Solverb) & 8.0 & 7.0 & $99.20(0.00)$ & $0.512(0.00)$ \\
\hline & BPNN & 8.0 & 7.0 & $99.18(0.02)$ & $0.513(0.20)$ \\
\hline & Partial Cubic RS & 8.0 & 7.0 & $99.15(0.05)$ & $0.500(2.34)$ \\
\hline & Quadratic RS & 8.0 & 7.0 & $99.17(0.03)$ & $0.531(3.71)$ \\
\hline & Model & 8.0 & 7.0 & 99.20 & 0.512 \\
\hline \multirow[t]{6}{*}{8} & RBNN (Solverbe) & 8.0 & 7.0 & $99.40(0.00)$ & $0.493(0.00)$ \\
\hline & RBNN (Solverb) & 8.0 & 7.0 & $99.40(0.00)$ & $0.493(0.00)$ \\
\hline & BPNN & 8.0 & 7.0 & $99.41(0.01)$ & $0.500(1.42)$ \\
\hline & Partial Cubic RS & 8.0 & 7.0 & $99.42(0.02)$ & $0.499(1.22)$ \\
\hline & Quadratic RS & 8.0 & 70 & $99.67(0.27)$ & $0.47 !(4.46)$ \\
\hline & Model & 8.0 & 7.0 & 99.40 & 0.493 \\
\hline
\end{tabular}

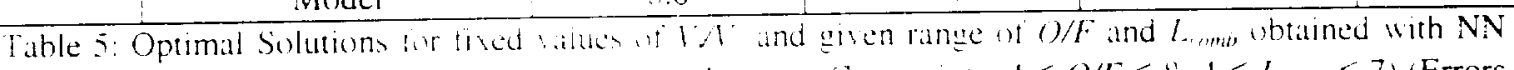
and RSM schemes for the shear colaxial injector element. (Constraints: $t \leq O / F \leq 8 . t \leq L_{\text {romb }} \leq 7$ ) (Errors are given in parenthesis for cach prediction is in th

\begin{tabular}{|c|c|c|c|c|}
\hline Type of RS & $\left.\sigma \operatorname{lin} m l^{\prime \prime}\right)$ & $\sigma$ for $\|(y)$ & $\sigma_{t, f o r} W(\%)$ & $\sigma$ for $W(\%)$ \\
\hline Quadratic RS & 2.507 & 0.863 & 0.788 & 1.281 \\
\hline Reduced Cubic RS & $: 949$ & $\mid, 0.31$ & 0.402 & 1.223 \\
\hline
\end{tabular}

Table 0 : Training and predicting error lor different response surtaces of the objective functions of the supersonic turbine. (Errors are given in percentages of the mealn value of the responses)

\begin{tabular}{|c|c|c|c|c|c|c|c|}
\hline \multirow[t]{2}{*}{ Scheme } & \multirow[t]{2}{*}{ \# of lavets } & \multicolumn{2}{|c|}{$\begin{array}{l}=\text { al neurons in the } \\
\text { midden laver }\end{array}$} & \multicolumn{2}{|c|}{$\begin{array}{l}\text { al neurons in the } \\
\text { output laver }\end{array}$} & \multicolumn{2}{|c|}{$\begin{array}{l}\text { Error solal aimed for } \\
\text { during training }\end{array}$} \\
\hline & & $\because$ & 11 & 11 & IV & 11 & $W$ \\
\hline RBNN Solverbes & $\therefore$ & -6 & 9 & $!$ & 1 & $\begin{array}{c}1) .0 \\
\{s c=9.50\}\end{array}$ & $\begin{array}{c}0.0 \\
\{s c=9.45\}\end{array}$ \\
\hline RBNN (Solverb) & - & 37 & 75 & 1 & 1 & $\begin{array}{c}0.001 \\
\{s c=6.50\}\end{array}$ & $\begin{array}{c}0.001 \\
\{s c=8.35\} \\
\end{array}$ \\
\hline BPNN & 2 & 5 & 60) & $!$ & 1 & 0.001 & 0.001 \\
\hline
\end{tabular}

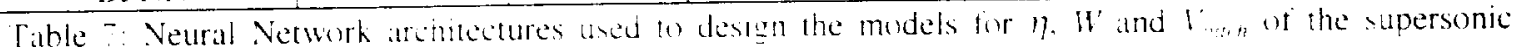
turbine. ; $c=$ spread comsum

\begin{tabular}{|c|c|c|}
\hline Scheme & $\sigma$ for $\eta(\%)$ & $\sigma$ for $W(\%)$ \\
\hline RBNN (Solverbe) & 1.251 & 1.096 \\
\hline RBNN (Solverb) & 0.292 & 1.102 \\
\hline BPNN & 0.777 & 2.563 \\
\hline Reduced Cubic RS & 1.031 & 1.223 \\
\hline
\end{tabular}

Table 8: RMS error in predicting the values of the objective function by various schemes for the supersonic turbine. (Error are given in percentages of the mean value of the responses) 
AIAA-2000-4880

\begin{tabular}{|c|c|c|c|c|c|c|c|c|c|c|c|}
\hline Scheme & $D$ & $R P M$ & $A_{\text {amn }}$ & $C_{r}$ & $C_{b}$ & $K_{r}$ & $\eta$ & $W$ & $V_{\text {puch }}$ & $A N^{2}$ & Apay \\
\hline $\begin{array}{c}\text { RBNN } \\
\text { (Solverbe) }\end{array}$ & 0.972 & 1.181 & 0.811 & 1.443 & 0.836 & 0.0 & $\begin{array}{c}0.810 \\
(5.80)\end{array}$ & $\begin{array}{c}0.636 \\
(0.74)\end{array}$ & 1.148 & 1.132 & $\begin{array}{c}-0.139 \\
(29.80)\end{array}$ \\
\hline Meanline & 0.972 & 1.181 & 0.811 & 1.443 & 0.836 & 0.0 & $\mathbf{0 . 7 6 6}$ & $\mathbf{0 . 6 4 1}$ & $\mathbf{1 . 1 4 8}$ & $\mathbf{1 . 1 3 2}$ & $\mathbf{- 0 . 1 9 7}$ \\
\hline $\begin{array}{c}\text { RBNN } \\
\text { Solverb) }\end{array}$ & 0.999 & 1.149 & 0.857 & 1.483 & 0.792 & 0.0 & $\begin{array}{c}0.785 \\
(1.75)\end{array}$ & $\begin{array}{c}0.653 \\
(0.17)\end{array}$ & 1.148 & 1.132 & $\begin{array}{c}-0.177 \\
(9.16)\end{array}$ \\
\hline Meanline & 0.999 & 1.149 & 0.857 & 1.483 & 0.792 & 0.0 & $\mathbf{0 . 7 7 2}$ & $\mathbf{0 . 6 5 4}$ & $\mathbf{1 . 1 4 8}$ & $\mathbf{1 . 1 3 2}$ & $\mathbf{- 0 . 1 9 4}$ \\
\hline BPNN & 1.024 & 1.121 & 0.901 & 1.168 & 1.143 & 0.0 & $\begin{array}{c}0.793 \\
(2.49)\end{array}$ & $\begin{array}{c}0.608 \\
(8.63)\end{array}$ & 1.148 & 1.132 & $\begin{array}{c}-0.153 \\
(21.49)\end{array}$ \\
\hline Meanline & 1.024 & 1.121 & 0.901 & 1.168 & 1.143 & 0.0 & $\mathbf{0 . 7 7 2}$ & $\mathbf{0 . 6 6 6}$ & $\mathbf{1 . 1 4 8}$ & $\mathbf{1 . 1 3 2}$ & $\mathbf{- 0 . 1 9 5}$ \\
\hline $\begin{array}{c}\text { Reduced } \\
\text { Cubic RS }\end{array}$ & 0.903 & 1.272 & 0.700 & 1.706 & 0.871 & 0.0 & $\begin{array}{c}0.758 \\
(1.50)\end{array}$ & $\begin{array}{c}0.591 \\
(2.10)\end{array}$ & 1.148 & 1.132 & $\begin{array}{c}-0.194 \\
(8.40)\end{array}$ \\
\hline Meanline & 0.903 & 1.272 & 0.700 & 1.706 & 0.871 & 0.0 & $\mathbf{0 . 7 4 6}$ & $\mathbf{0 . 6 0 4}$ & $\mathbf{1 . 1 4 8}$ & $\mathbf{1 . 1 3 2}$ & $\mathbf{- 0 . 2 1 1}$ \\
\hline
\end{tabular}

Table 9: Optimal Solutions with constraints on $V_{p \text { peth }}$ and $A N^{2}$ for a supersonic turbine. (Error given in parenthesis for each prediction is in $\%$. (All variables are normalized by their respective baseline values)
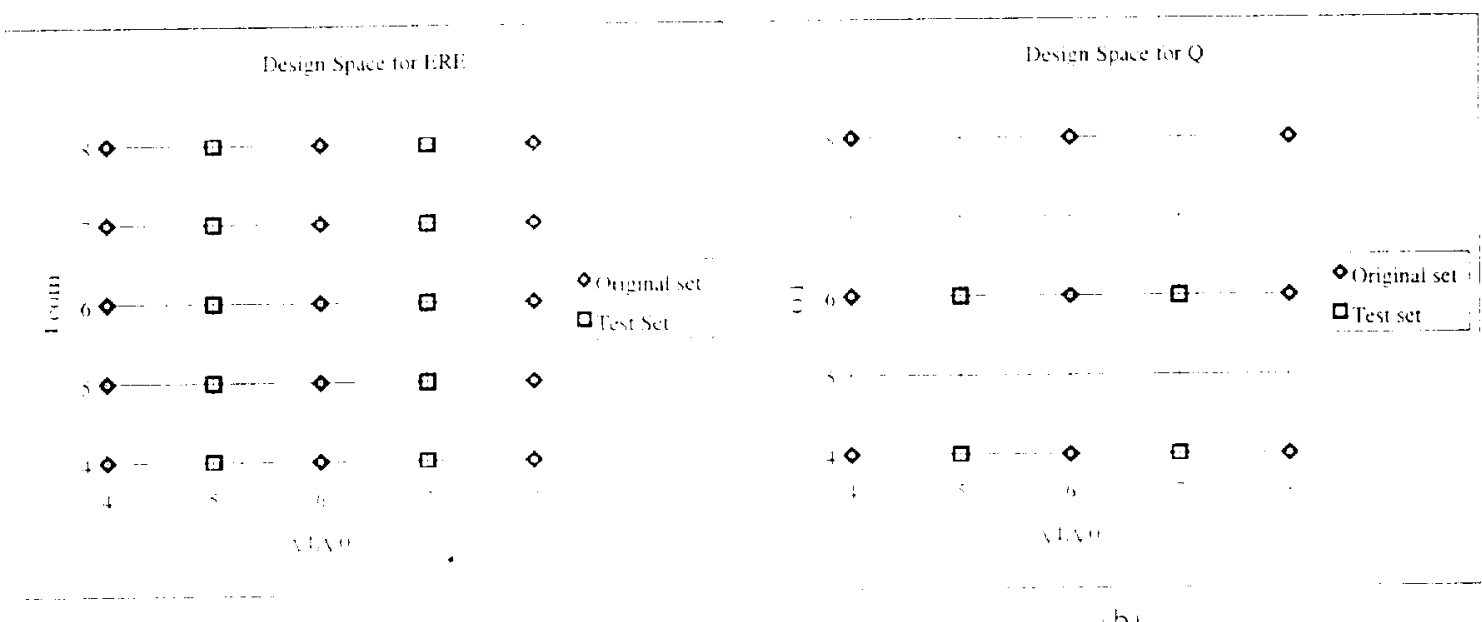

$: 11$

(1)

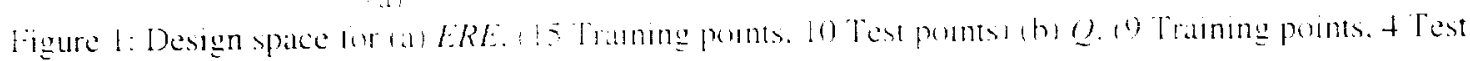
points) for the injector.

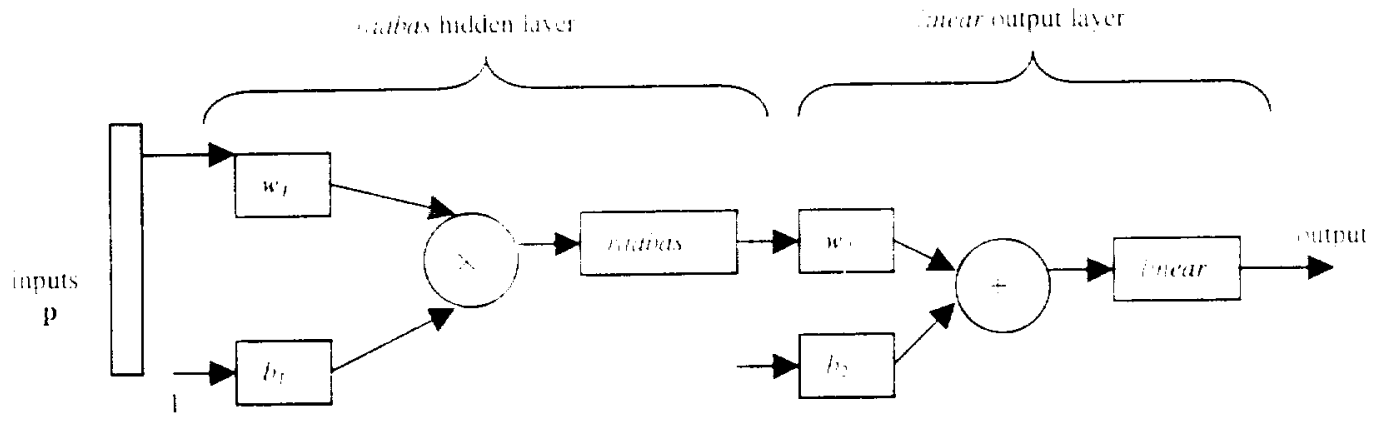

(al)

Figure 2: (i) Ratdial basis newwork. 


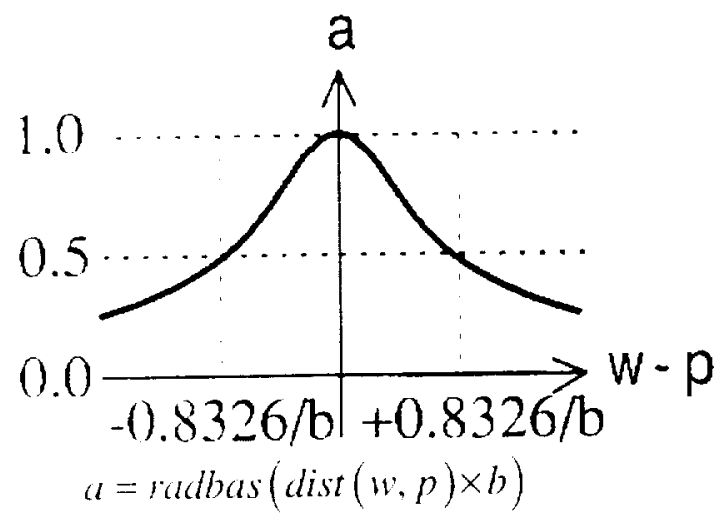

(b)

Figure 2: (b) Transfer function, radbas.

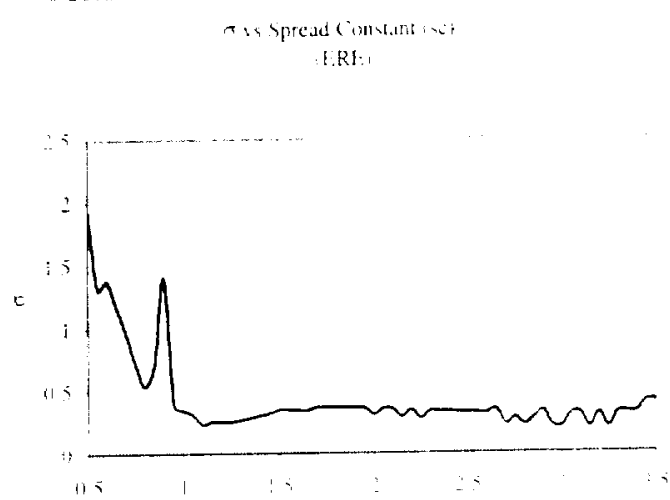

(i)
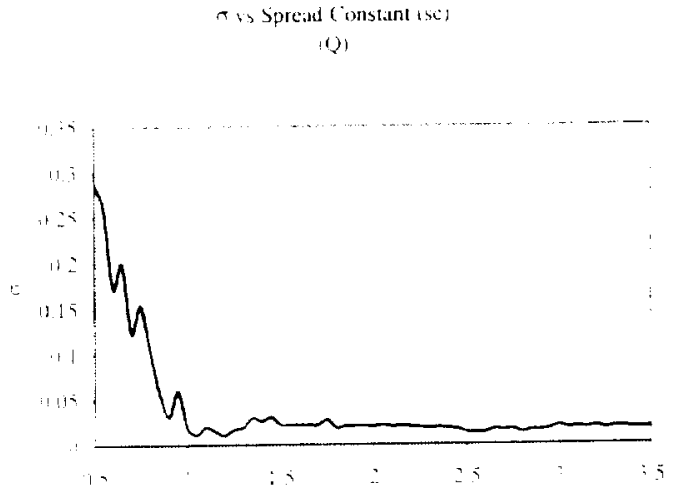

(b)

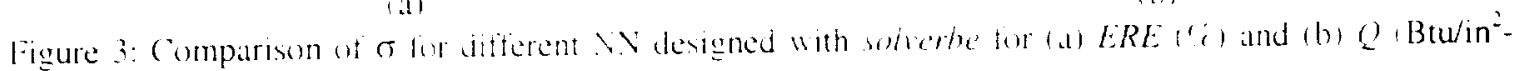
rect.

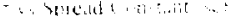

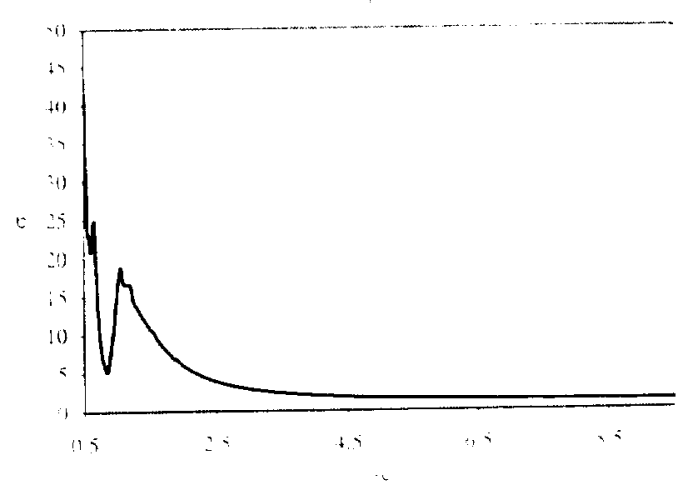

(a)

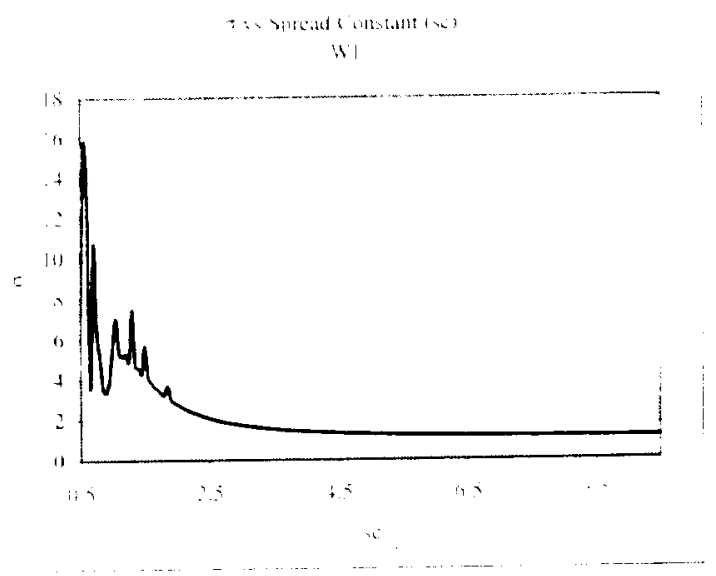

(b)

Figure 4: Comparison of $\sigma$ for different N.V designed with solverbe for (a) $\eta(\%)$ and (b) $W$ (lbs). 


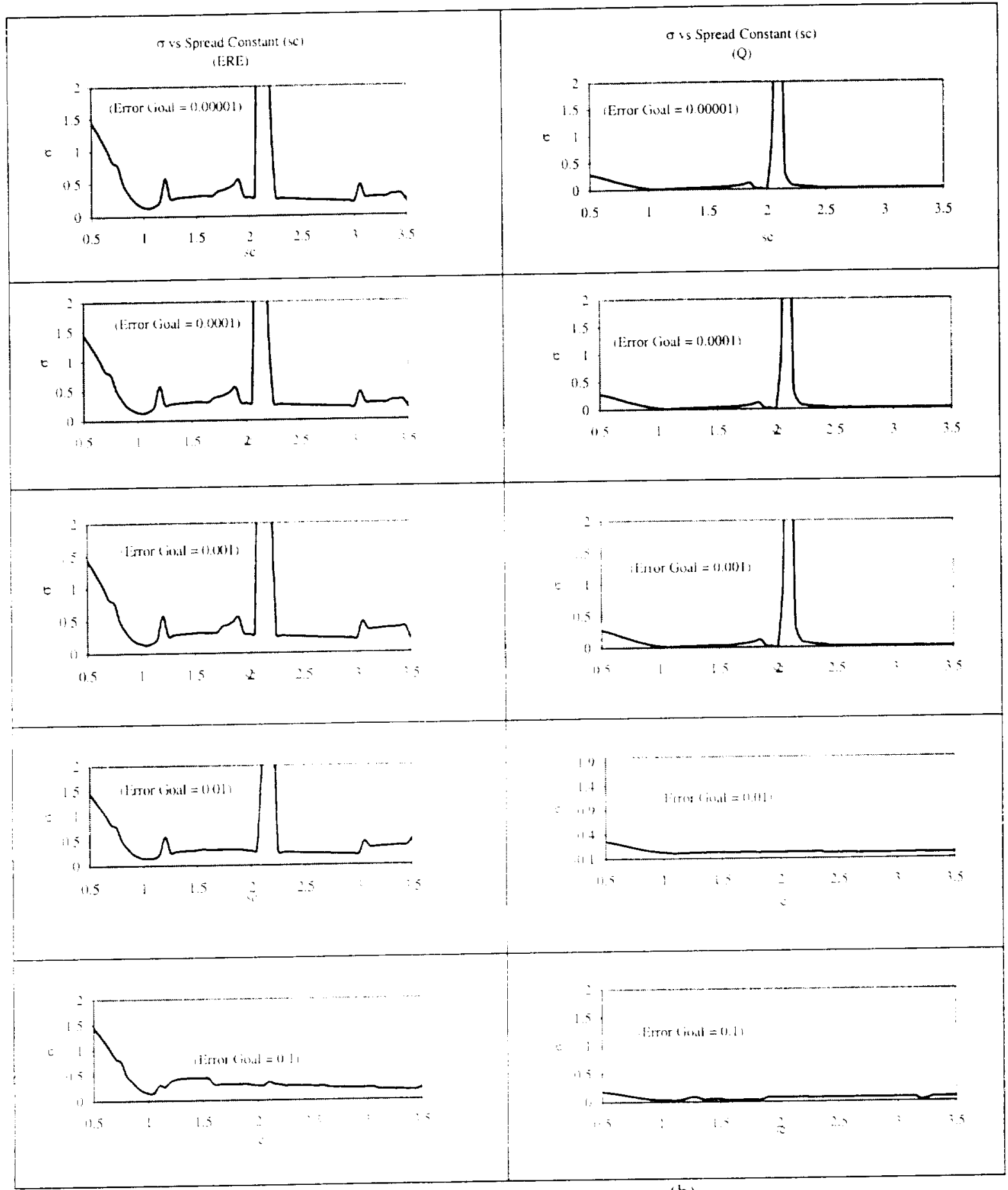

Figure 5: Comparison of $\sigma$ for different $N N$ designed with solverb for (a) $E R E(\%)$ and (b) $Q\left(\mathrm{Btu} / \mathrm{in}^{2}-\mathrm{sec}\right.$ ).

(b) 


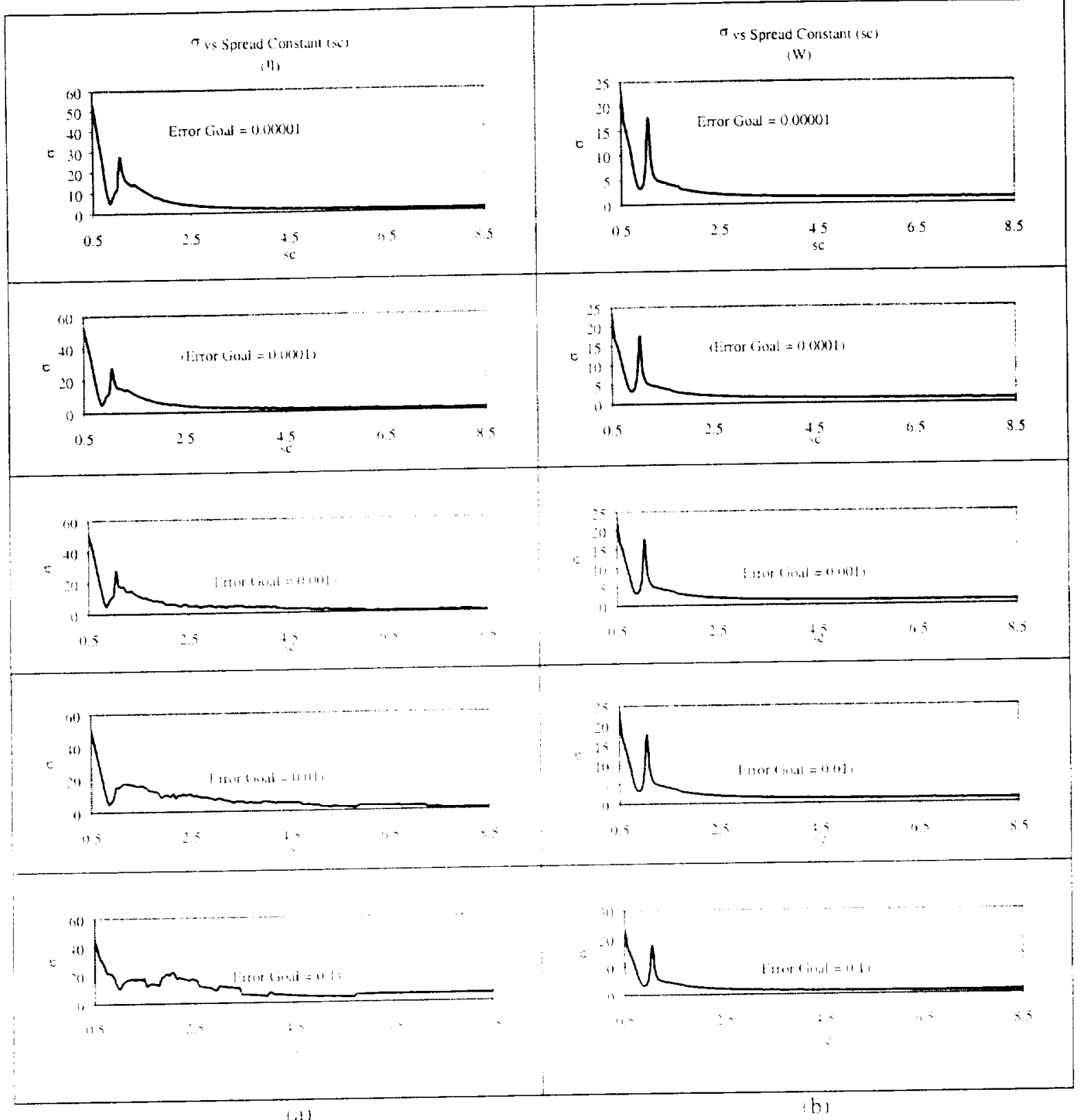

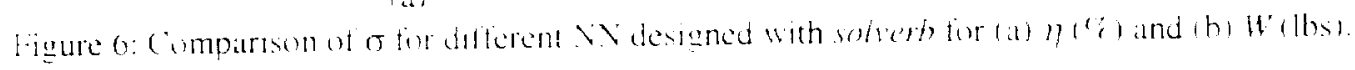


AIAA-2000-4880
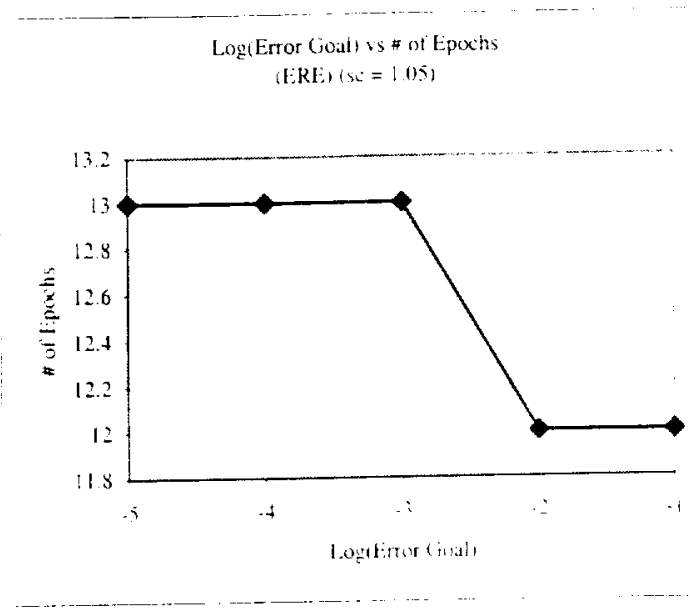

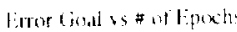

(Q) $100=1,05$

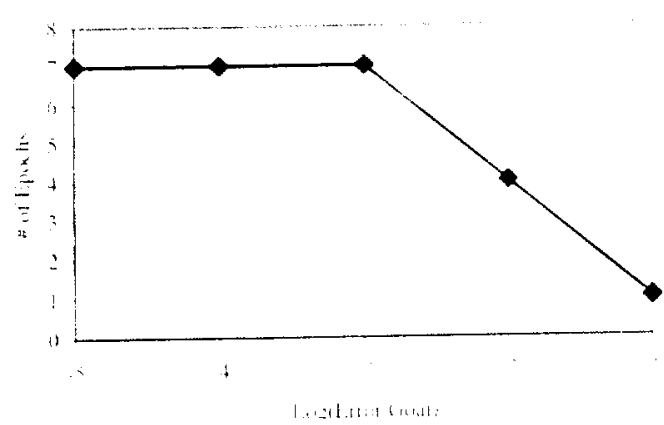

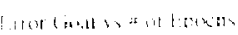

. $111 \mathrm{i} \mathrm{x}^{\circ}=64 \mathrm{x}$

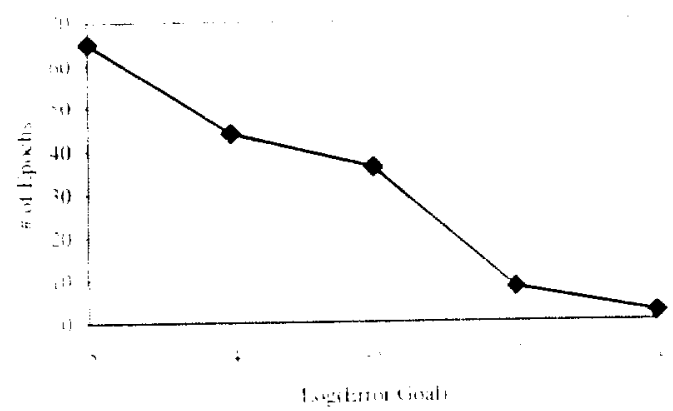

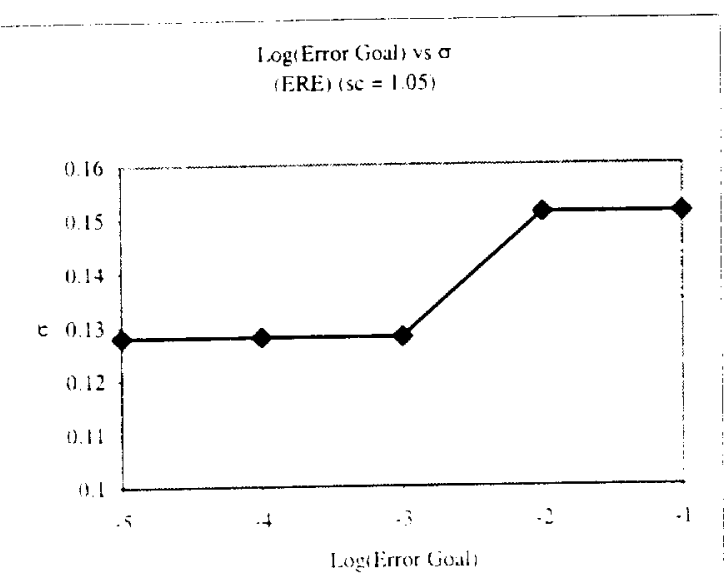

(il)

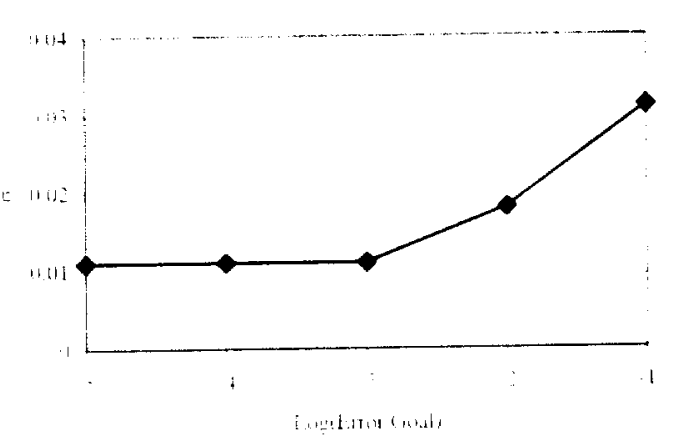

!)!

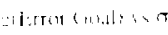

1) $190=0.110$

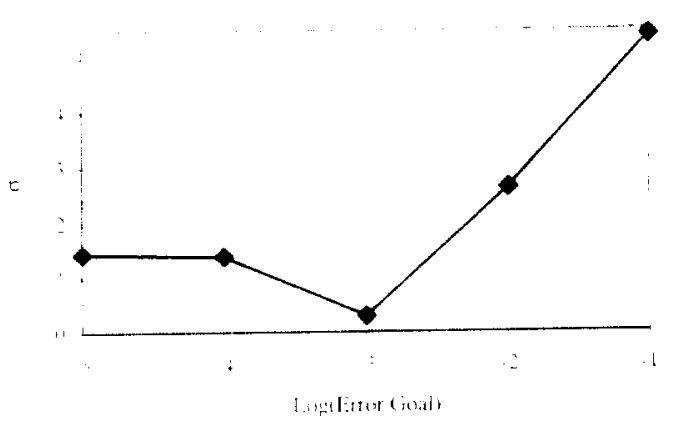

(c)

Figure 7: Comparison of Error goal is number of Epochs and $\sigma$ for networks trained with solverb. (a)

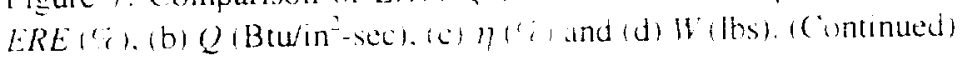


AIAA-2000-4880
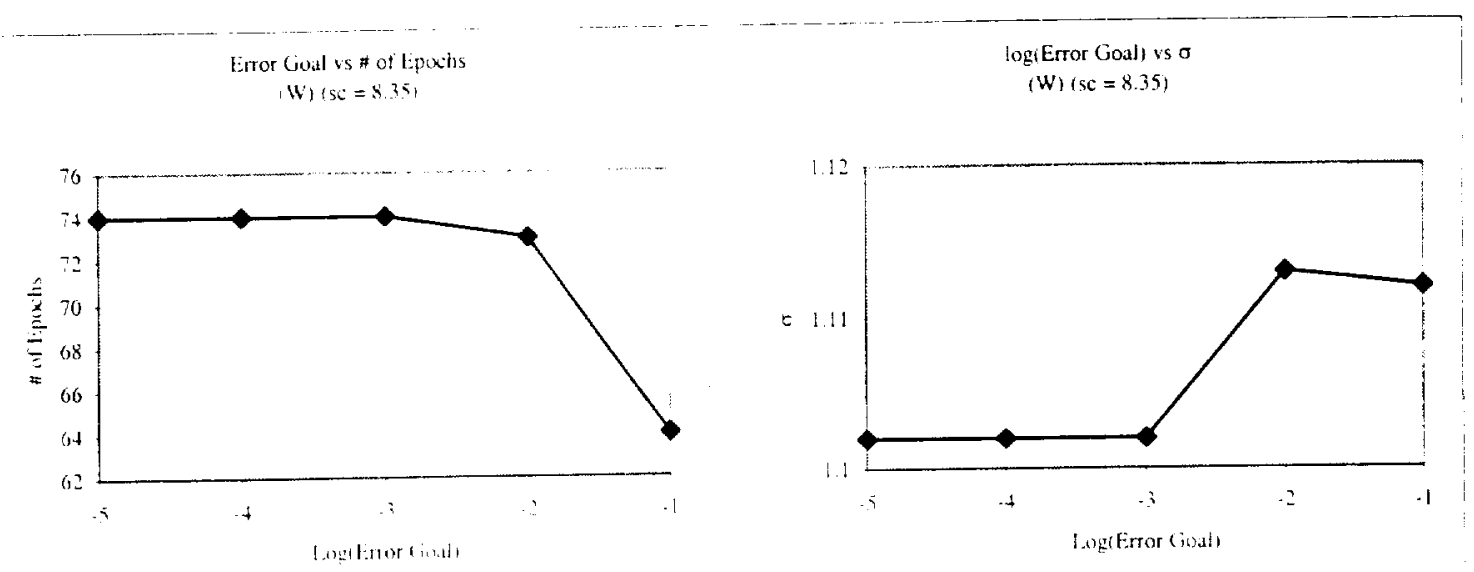

(d)

Figure 7: Comparison of Error woal w. number of Epochs and $\sigma$ for networks trained with solverb. (a) ERE (\%). (b) $Q\left(\mathrm{Btu} / \mathrm{in}^{2}\right.$-sec). (c) $)$ (') and (d) W (lhs).
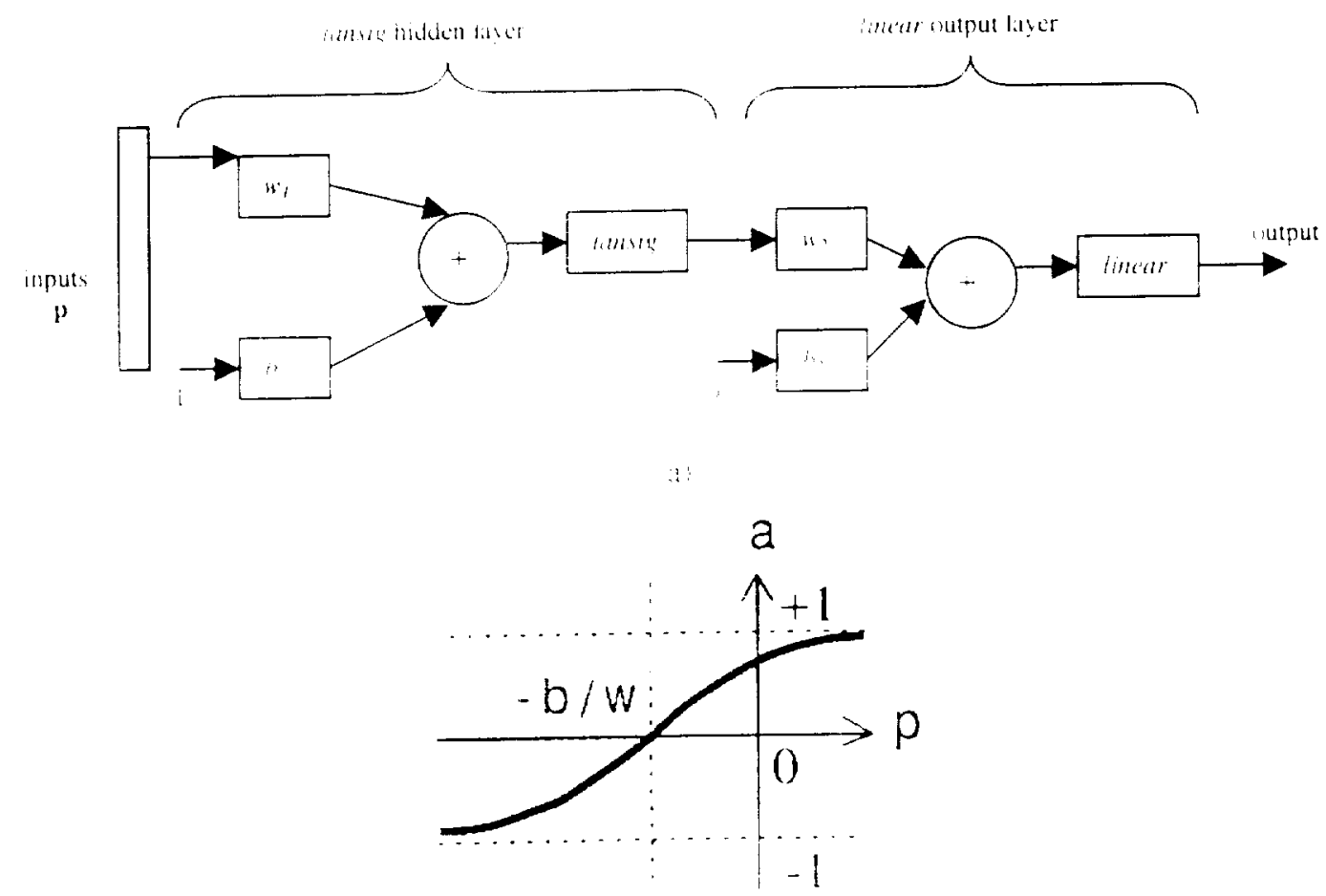

$$
u=t a n s i g(n+b)
$$

(b)

Figure S: (a) Back-propalgation Network, (b) Transter function. tansig. 
AIAA-2000-4880

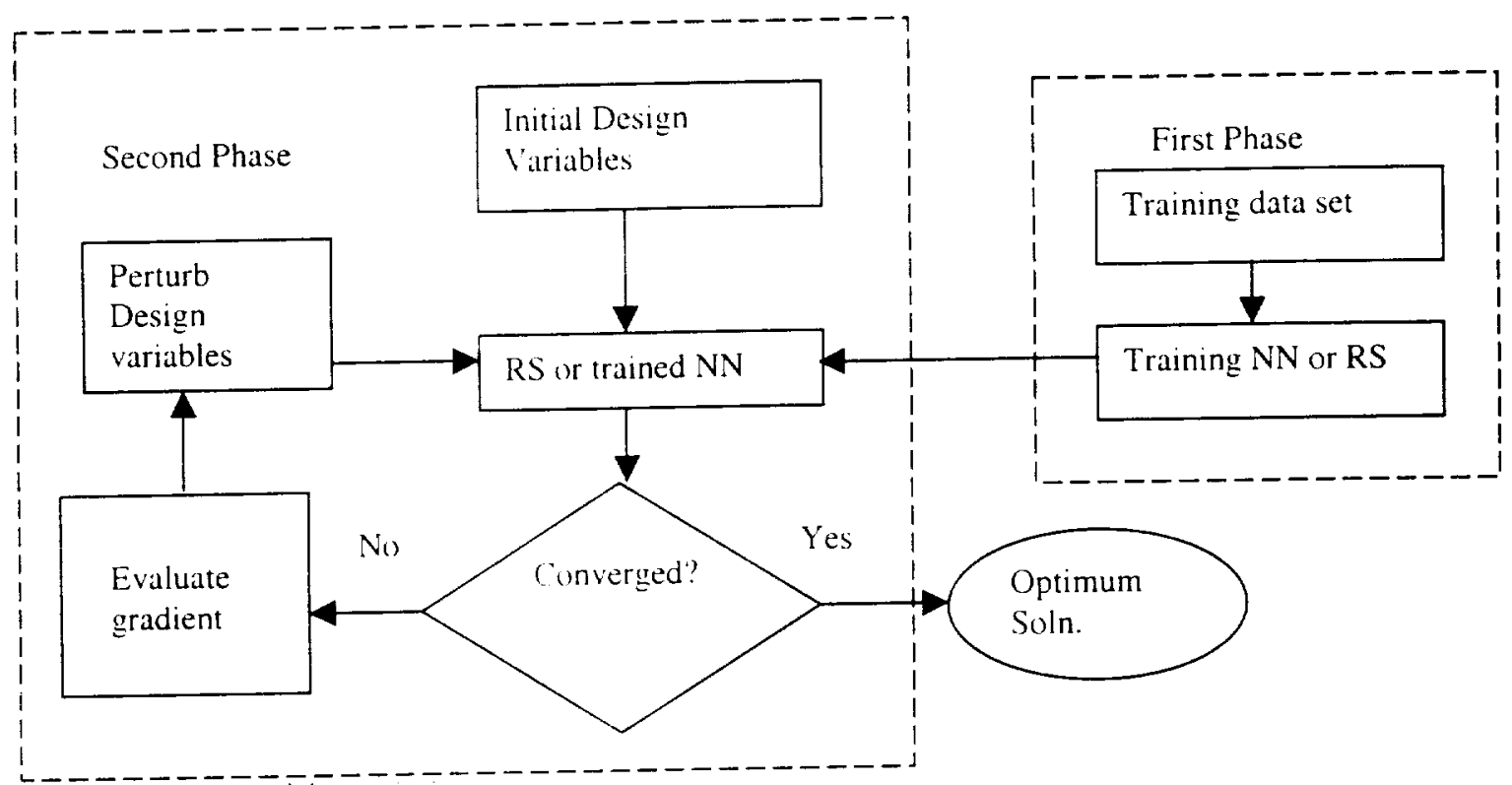

Figure 9 : Schemaric of the opumizanon process.

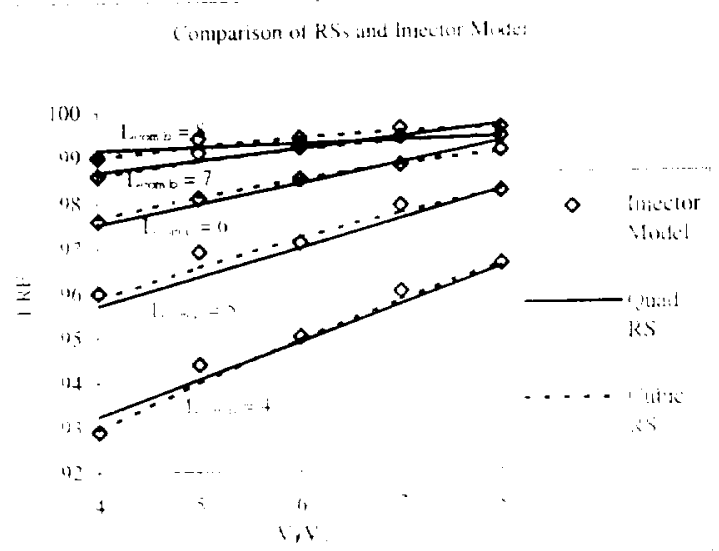

(a)

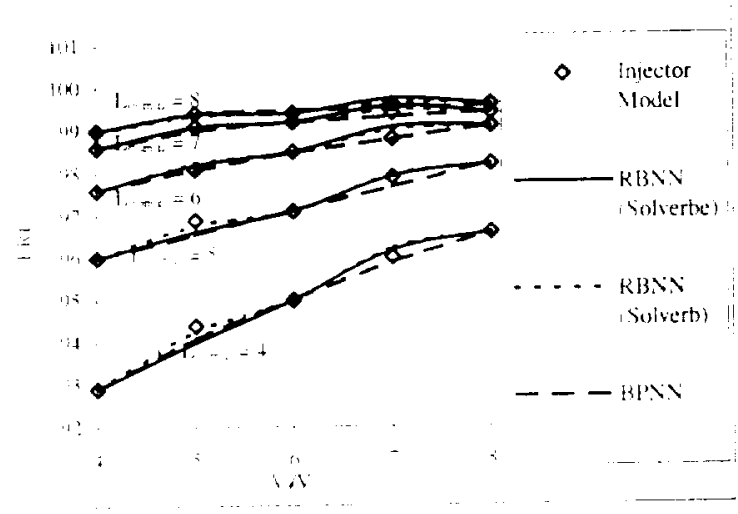

(b)

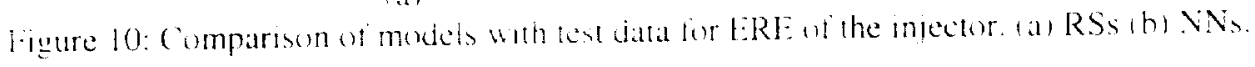

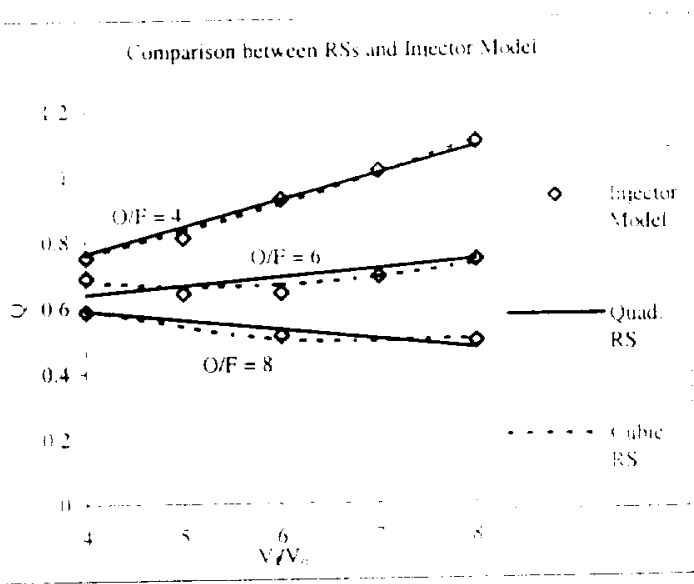

(a) (omparison between Vils and injector Moxdel

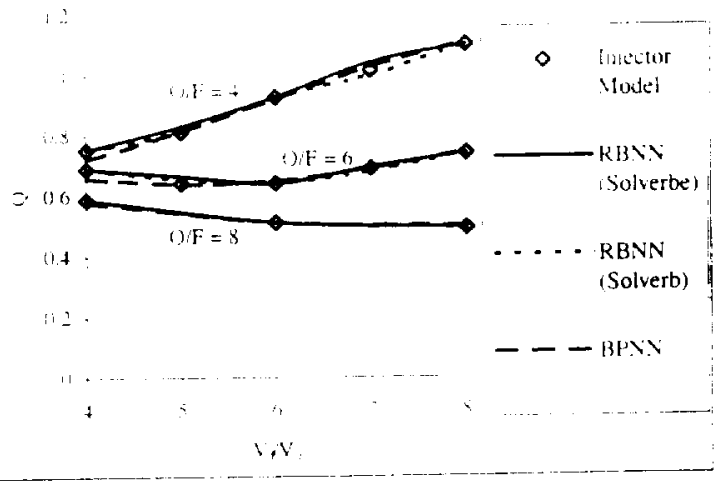

(b)

Figure 11: Comparison of models with test data for $Q$ of the injector. (a) RSs. (b) NNs. 
AIAA-2000-4880

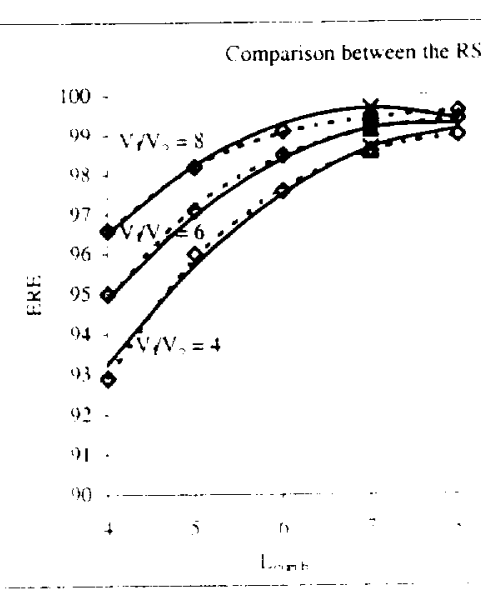

(i)

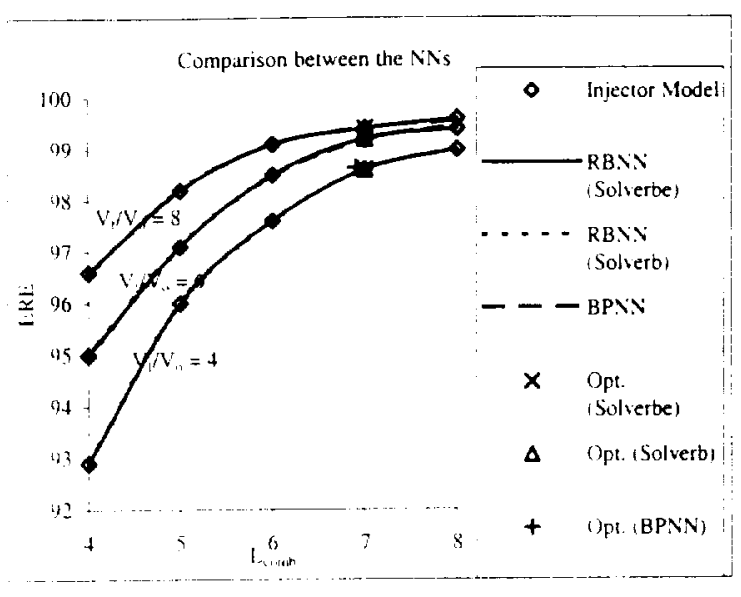

(b)

Figure 12: Performance of models for ERE of the injector. (a) RSs (b) NNs.

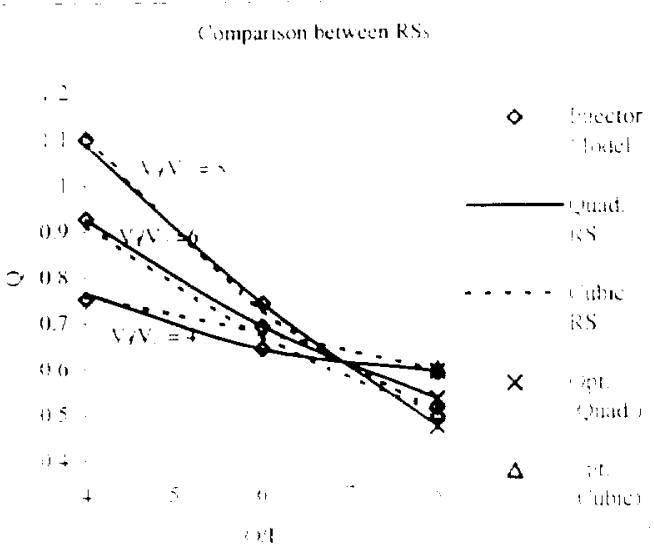

(1)

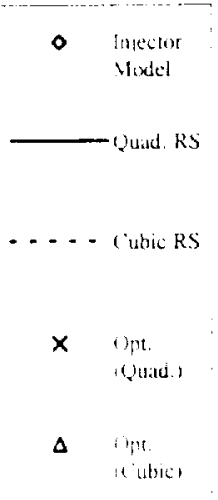


AIAA-2000-4880

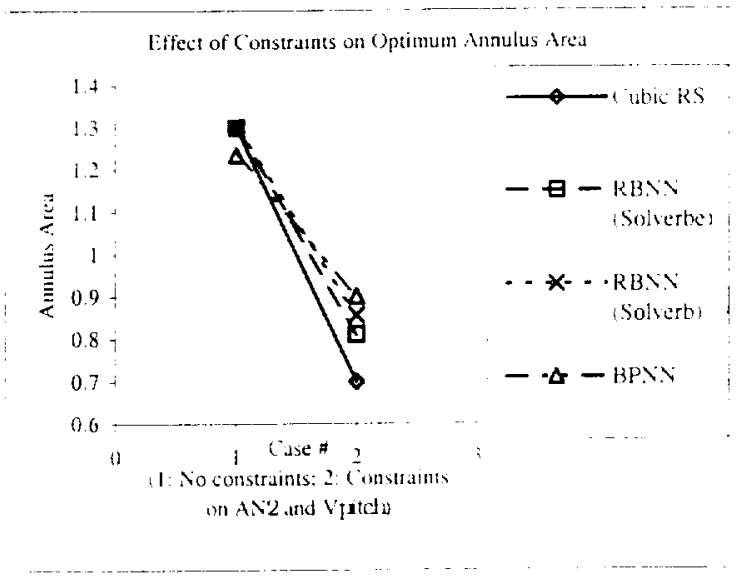

(c)

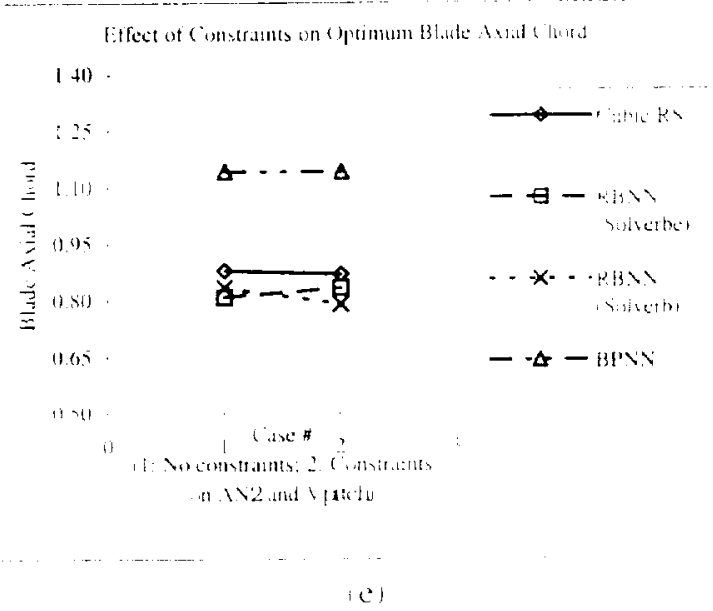

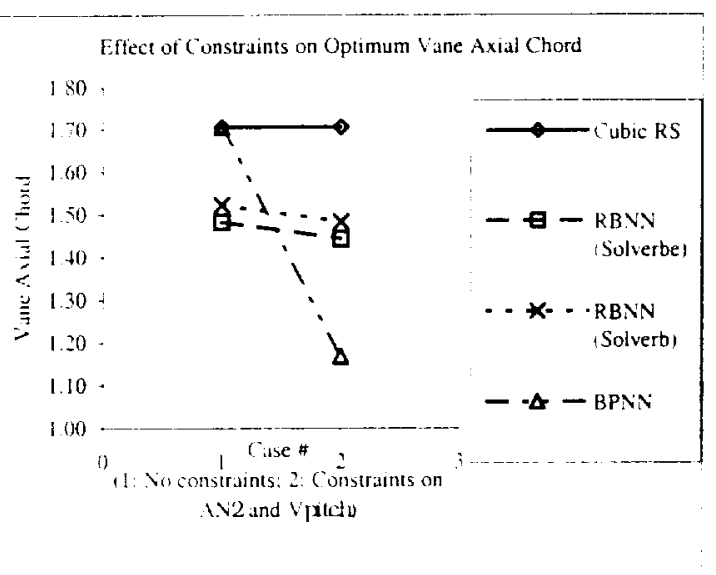

(d)

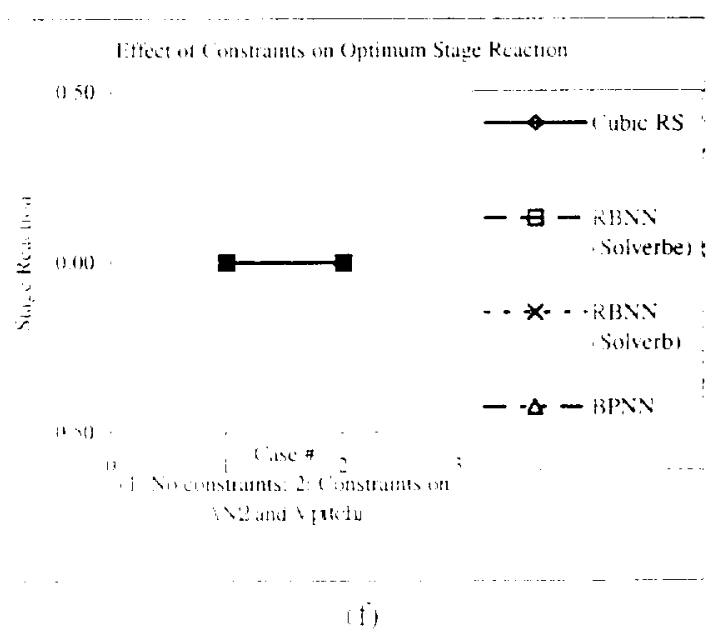

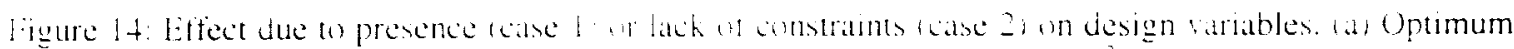

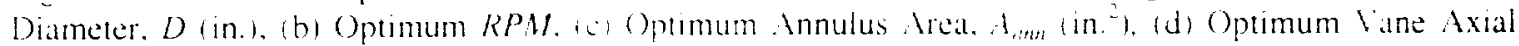

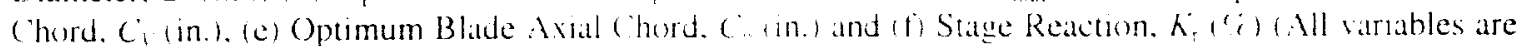
mormalized by their respective haselune salues.

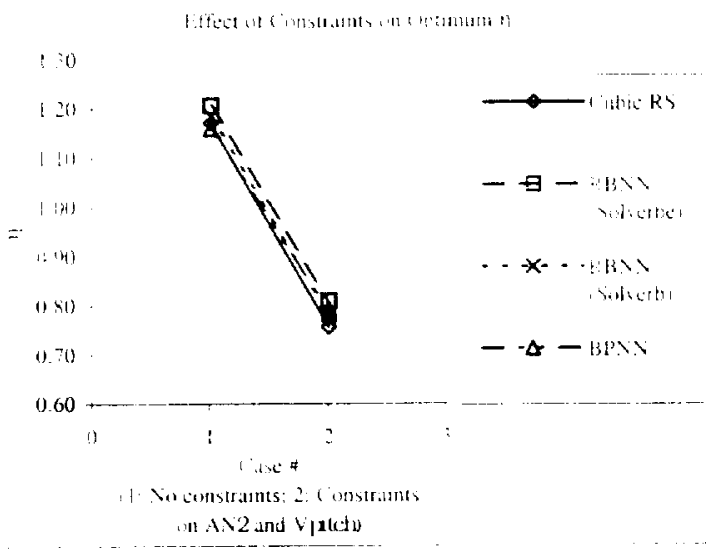

(a)

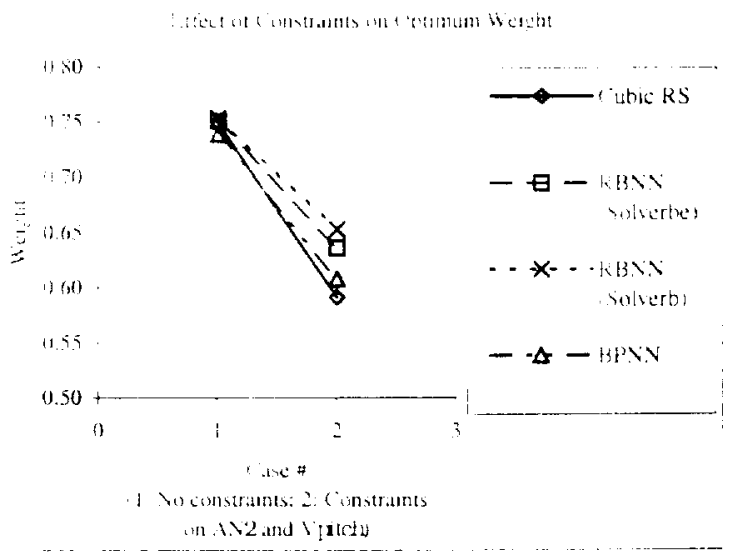

(b)

Figure 15: Effect due (o) presence (case 1) or lack of constraints (case 2) on objective functions. (a) Optimum Efficiency. $\eta(\%)$, (b) Optimum Weight. W' (lbs), (c) Optimum pitch speed. $V_{\text {puth }}$ (in. /sec), (d) Optimum Annulus Area X RPM. A $V^{2}\left(\mathrm{in}^{2} \times \mathrm{rpm}^{2}\right.$ ) and (e) Optimum Incremental Payload. Jpay (lbs) (All variables are normalized by their respective baseline values) (Continued). 
AIAA-2000-4880

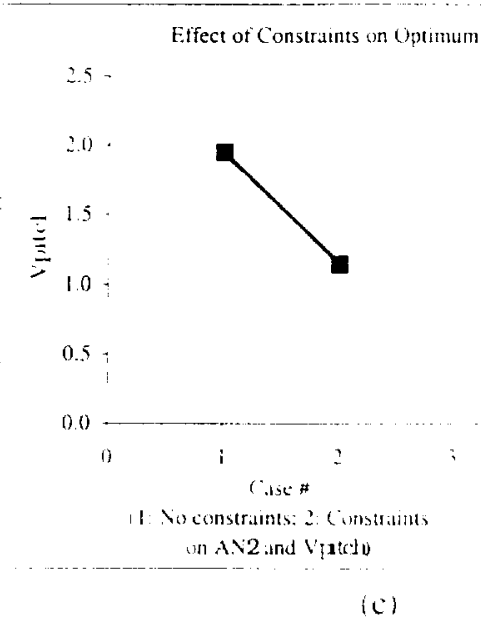

(c)

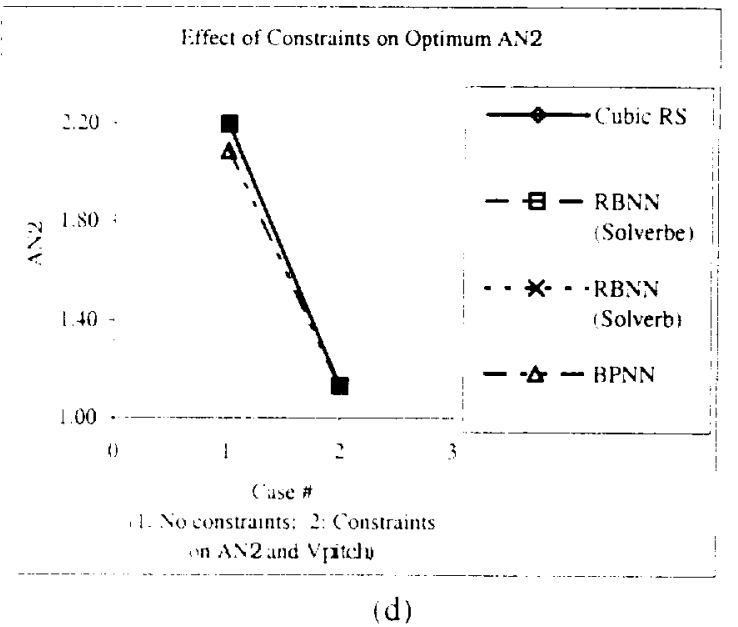

(d)

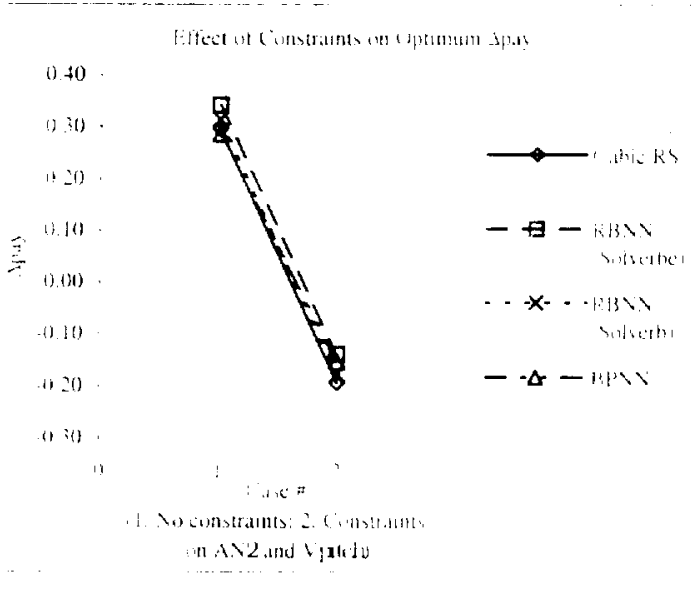

(3)

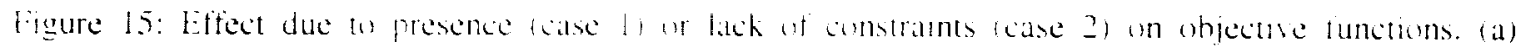

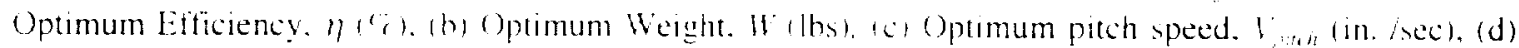

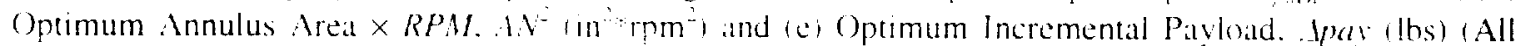

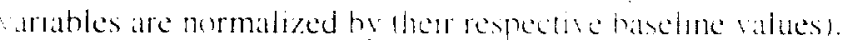

